\title{
Antibody Recognition and Conformational Flexibility of a Plaque-Specific $\beta$-Amyloid Epitope Modulated by Non-native Peptide Flanking Regions
}

\author{
Marilena Manea, ${ }^{\dagger, \$}$ Adrián Kalászi, ${ }^{\dagger, \$, \triangle}$ Gábor Mező, ${ }^{\perp}$ Kata Horváti, ${ }^{\perp}$ Andrea Bodor, ${ }^{\#}$ Anikó Horváth, ${ }^{\perp}$ Ödön Farkas, ${ }^{\S, \Delta}$ \\ András Perczel, ${ }^{\triangle, \nabla}$ Michael Przybylski, ${ }^{\dagger}$ and Ferenc Hudecz ${ }^{*, \triangle, \perp}$ \\ Laboratory of Analytical Chemistry and Biopolymer Structure Analysis, University of Konstanz, 78457 Konstanz, Germany, Laboratory of \\ Chemical Informatics, Institute of Chemistry, Eötvös L. University, 1117 Budapest, Hungary, Research Group of Peptide Chemistry, Hungarian \\ Academy of Sciences, Eötvös L. University, 1117 Budapest, Hungary, Department of Organic Chemistry, Eötvös L. \\ University, 1117 Budapest, Hungary, Laboratory of Structural Chemistry and Biology, Institute of Chemistry, Eötvös L. University, \\ 1117 Budapest, Hungary, and Protein Modelling Group, Hungarian Academy of Sciences, Institute of Chemistry, Eötvös L. University, \\ 1117 Budapest, Hungary
}

\begin{abstract}
Here we report on the synthesis, antibody binding, and QSAR studies of a series of linear and cyclic peptides containing a $\beta$-amyloid plaque-specific epitope (A $\beta(4-10)$; FRHDSGY). In these constructs, two or three $\alpha$-L-Ala, $\alpha$-D-Ala, or $\beta$-Ala residues were introduced at both $N$ - and $C$-termini of the epitope as non-native flanking sequences. Cyclization of the linear $\mathrm{A} \beta(4-10)$ epitope peptide resulted in reduced antibody binding. However, the antibody binding could be fully compensated by insertion of alanine flanks into the corresponding cyclic peptides. These results indicate that the modification of a $\beta$-amyloid plaque-specific epitope by combination of cyclization and flanking sequences could generate highly antigenic peptides compared to the native sequence. A novel 3D QSAR method, which explicitly handles conformational flexibility, was developed for the case of such molecular libraries. This method led to the prediction of the binding conformation for the common FRHDSGY sequence.
\end{abstract}

\section{Introduction}

The accumulation and fibrillar association in plaques of $\beta$-amyloid (A $\beta)$, a self-aggregating peptide of $39-43$ residues, in brain is generally thought to be the cause of cognitive decline and neurodegeneration in Alzheimer's disease $(\mathrm{AD})^{a} .{ }^{1-3} \mathrm{Re}-$ cently, possible therapeutic approaches for treatment of $\mathrm{AD}$ have been pursued, aimed at the enhancement of amyloid clearance via active or passive immunization by anti- $\mathrm{A} \beta$ antibodies. In transgenic mouse models of $\mathrm{AD}$, several laboratories have demonstrated that therapeutically effective antibodies raised against $\mathrm{A} \beta(1-42)$ and/or its oligomeric assemblies decrease $\mathrm{A} \beta$ fibrillogenesis and cytotoxicity and are capable to exert therapeutic effects. ${ }^{1-6} \mathrm{We}$ found previously that these therapeutically active antibodies specifically target the $N$-terminal A $\beta(4-10)$ epitope sequence FRHDSGY. ${ }^{7}$ The recognition specificity and properties of this epitope and derived peptides may provide a lead structure both for development of new specific $\mathrm{AD}$ vaccines and for molecular diagnostic applications.

Several approaches have been developed in order to modify the immunorecognition of linear peptides representing B- or T-cell epitopes and to increase their enzymatic stability: (i)

* To whom correspondence should be addressed at the Hungarian Academy of Sciences. Phone: (+36)-1-209-0555. Fax: (+36)-1-372-2620. E-mail: fhudecz@ludens.elte.hu.

${ }^{\dagger}$ Laboratory of Analytical Chemistry and Biopolymer Structure Analysis, University of Konstanz.

‡ M.M. and A.K. contributed equally to this work.

$\S$ Laboratory of Chemical Informatics, Eötvös L. University.

$\triangle^{\triangle}$ Department of Organic Chemistry, Eötvös L. University.

${ }^{\perp}$ Research Group of Peptide Chemistry, Eötvös L. University.

${ }^{\#}$ Laboratory of Structural Chemistry and Biology, Eötvös L. University.

$\nabla$ Protein Modelling Group, Eötvös L. University.

a Abbreviations: AD, Alzheimer's disease; $\mathrm{A} \beta, \beta$-amyloid peptide; a, $\alpha$-D-alanine; QSAR, quantitative structure-activity relationship; BC, binding conformation; RCs, reference conformers, ACs, anchor conformations; MD, molecular dynamics. synthesis of cyclic and/or chimeric peptides; ${ }^{8-11}$ (ii) modification of the flanking regions connected to the $N$ - and/or $C$-terminus of a core epitope; ${ }^{12,13}$ and (iii) multiplication of copies of a defined number of B- or T-cell epitopes by conjugation to carrier molecules. ${ }^{14}$ Recent work in our laboratories has been focused on the preparation and characterization of various bioconjugates as potential lead structures for $\mathrm{AD}$ vaccination. ${ }^{15}$ Thus, the A $\beta(4-10)$ epitope was elongated by either an $N$-terminal -Cys$(\mathrm{Gly})_{5}$ - or a $C$-terminal -(Gly) $)_{5}$-Cys- sequence, and it was attached via thioether linkage to different polylysine-based branched chain polypeptide carriers with either Ser (SAK) or Glu (EAK) residues at the end of the branches. ${ }^{15}$ In a second type of conjugates, the $\mathrm{A} \beta(4-10)$ epitope alone, or flanked by $\alpha$-L- or $\beta$-alanine dimers at the $N$ - and $C$-terminal sides, was coupled via amide bonds to (i), a tetratuftsin derivative (Ac$[\mathrm{TKPKG}]_{4}-\mathrm{NH}_{2}$ ), or (ii), to a carrier peptide elongated by a promiscuous helper T-cell epitope (Ac-FFLLTRILTIPQSLD$[\mathrm{TKPKG}]_{4}-\mathrm{NH}_{2}$ ). ${ }^{16}$ The evaluation of these conjugates showed that the type of the carrier, the epitope topology, the presence of a spacer group between the epitope and carrier, and of flanking regions all had significant effects on the antibody recognition of the $\mathrm{A} \beta(4-10)$ epitope. In particular, the introduction of $\beta$-alanine residues as flanks to both $N$ - and $C$-termini of the epitope provided a marked increase of antibody binding. One of our previous studies demonstrated that the replacement of amino acids by their D isomers at the $\mathrm{N}$-terminus of an epitope peptide increased its enzymatic stability in human sera. ${ }^{12}$ In contrast, the substitution of the L-amino acids by the D form at the $C$-terminus prevents the enzyme digestion in lysosomal fractions. We could conclude that the incorporation of two to three D-amino acid residues to both $N$ - and $C$-termini can result in high stability of epitope peptides in complex biological matrices. In another experiment, we found that the cyclization via disulfide bridge formation between cysteine residues attached to the $N$ - and $C$-terminal positions may increase the stability of 
the biological active conformation of the epitope sequence. However, the enzymatic stability of the peptide increased only moderately in human sera compared to the linear epitope. ${ }^{11}$ These results prompted us to evaluate systematically the effects of $\alpha-\mathrm{L}-, \beta$-, and $\alpha$-D-alanine flanking regions on antigenicity and conformation of linear and cyclic peptides containing the $\beta$-amyloid(4-10) epitope.

In the present study, we found that the presence of non-native L- and D-alanine (the latter will be marked in the text with "a" as one letter code) flanking sequences caused a significant increase of antibody recognition in linear $\beta$-amyloid(4-10) epitope peptides, while cyclization of the native $\mathrm{A} \beta(4-10)$ epitope resulted in lower antibody binding. However, this decrease of antibody recognition in cyclopeptides could be compensated by flanking alanine dimers or trimers at both $\mathrm{N}$ and $C$-termini. We also show that the type of flanking regions has a significant effect on the conformation of both linear and cyclic peptides, the presence of $\mathrm{L}-\mathrm{Ala}_{2}$ and $\mathrm{L}-\mathrm{Ala}_{3}$ or $\beta$-Ala

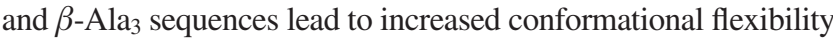
in the core epitope region.

To gain insight into the conformational properties of the analyzed peptides and to predict the binding conformation, a novel 3D QSAR computation was performed. 3D QSAR methods that account for the conformational flexibility have been evolved $^{17-22}$ during the past decade; however, the structures examined in most cases contain few rotable bonds, and the conformational space is usually sampled by some representative low energy conformers. Usually the bioactive conformation is a priori unknown, which may result in poor predictive capability. On the other hand, there is a limited number of efforts to develop methods specially designed to predict the binding conformation for molecules containing substantial number of rotable bonds. ${ }^{23,24}$ Such generally applicable computational tool was developed and its operation is demonstrated on the peptides analyzed in this study.

\section{Theoretical Background}

The analyzed molecules have a significant number of rotable bonds and have a common structural feature, the FRHDSGY epitope motif, which interacts with the antibody-binding site (paratope). We designate this active core region as CORE. The off-CORE parts in each single molecule vary from each other, and the working hypothesis is that their direct interaction with the binding site can be neglected by definition. The off-CORE exhibits an influence on the binding activity indirectly, only by modifying the conformational behavior of the flexible CORE. The major goal of our novel 3D QSAR method is to locate the binding conformation of the CORE, which can be found in the bound state. In this process, no information about the 3D structure of the active site is known, but the experimental activity of each molecule is used.

Consider the process of binding of a flexible molecule to the active site of a target protein. The binding free energy, $\Delta G$ bindtot, is independent of the actual reaction path, so we may split it into two parts. ${ }^{25}$ The first part can be the formation of the binding conformation (BC) in solution and the corresponding free energy change is denoted as $\Delta G_{\text {conf. }}$ The second part is the "rigid" binding of the $\mathrm{BC}$ to the active site, the corresponding free energy change is, $\Delta G_{\text {bind }}$.

$$
\Delta G_{\text {bind-tot }}=\Delta G_{\text {conf }}+\Delta G_{\text {bind }}
$$

The concentration of the complex, [IR], depends on the free energy change related to the whole binding process, while the concentration of $\mathrm{BC}$ in solution, $\left[I_{\mathrm{BC}}\right]$, depends only on $\Delta G_{\mathrm{conf}}$ (eqs 2 and 3).

$$
\begin{gathered}
{[\mathrm{IR}]=\left[\mathrm{I}_{0}\right]_{e}^{-\beta\left(\Delta G_{\mathrm{conf}}+\Delta G_{\mathrm{bind}}\right)}} \\
{\left[\mathrm{I}_{\mathrm{BC}}\right]=\left[\mathrm{I}_{0}\right]_{e}^{-\beta\left(\Delta G_{\mathrm{conf}}\right)}}
\end{gathered}
$$

where $\left[\mathrm{I}_{0}\right]$ is the concentration of the most stable conformer in solution. The fraction of $[\mathrm{IR}]$ and $\left[\mathrm{I}_{\mathrm{BC}}\right]$ depends only on the $\Delta G_{\text {bind }}$ value (eq 4). If the quotient is expanded by the total concentration of the inhibitor (in our case the epitope peptide) in solution, $I_{\text {tot }}$, the relative concentration or molfraction of the bound conformer is obtained in the numerator. We may also replace the relative concentration of the binding conformation in solution, the denominator, by the proportion of the conformations in a simulated trajectory, as the quotient of the frequency of $\mathrm{BC}\left(f_{\mathrm{BC}}\right)$ and the total number of steps, $n_{\text {traj }}$, in a trajectory which adequately represents the conformational distribution of the flexible molecule in solution.

$$
\frac{\left[\mathrm{I}_{\mathrm{BC}}\right]}{\left[\mathrm{I}_{\mathrm{BC}}\right]}=e^{-\beta \Delta G_{\text {bind }}}=\frac{\frac{[\mathrm{IR}]}{I_{\text {tot }}}}{\frac{\left[\mathrm{I}_{\mathrm{BC}}\right]}{I_{\text {tot }}}}=\frac{\frac{[\mathrm{IR}]}{I_{\text {tot }}}}{\frac{f_{\mathrm{BC}}}{n_{\text {traj }}}}
$$

The free energy change associated to the rigid binding can be considered as the sum of the energy changes due to the conformational change of the active site, the desolvation effect, the formation of the receptor-ligand interaction, and the freezing of the translational and rotational degrees of freedom of the ligand during binding. These members can be regarded as constant for the peptides of this set as these molecules are specially designed to bind only via the CORE region. Hence, the $\Delta G_{\text {bind }}$ values for each molecule are considered to be equal.

$$
\Delta G_{\text {bind }}^{i}=\Delta G_{\text {bind }}^{j}
$$

It follows from eqs 4 and 5 that the ratios of the relative concentrations of bound molecules for any member pairs of the molecular library should be close to the ratios of the probabilities of their BCs observed via the MD simulations in solution.

$$
\frac{\frac{\left[\mathrm{IR}^{i}\right]}{I_{\mathrm{tot}}}}{\frac{f_{\mathrm{BC}}^{i}}{n^{i}}}=\frac{\frac{\left[\mathrm{IR}^{j}\right]}{I_{\mathrm{tot}}}}{\frac{f^{j}}{n^{j}}} \Rightarrow \frac{\frac{\left[\mathrm{IR}^{i}\right]}{I_{\mathrm{tot}}}}{\frac{\left[\mathrm{IR}^{j}\right]}{I_{\mathrm{tot}}}}=\frac{\frac{f^{i}}{n^{i}}}{\frac{f^{j}}{n^{j}}}
$$

The relative concentration of the bound molecules can be determined from the results of well established experimental methods. In the present case, we used the $I_{50}$ values obtained from an indirect ELISA experiment $\left(I_{50}\right.$ represents the antigen concentration needed for obtaining an $\mathrm{OD}=1$ at $450 \mathrm{~nm}$ ).

During this experiment, the binding of the ligand, eq 7 , competes with the binding of the inhibitor or epitope peptide, eq 8 .

$$
\begin{gathered}
K_{\mathrm{d}}=\frac{[\mathrm{L}][\mathrm{R}]}{[\mathrm{LR}]}[\mathrm{L}] \approx L_{\mathrm{tot}} \\
K_{i}=\frac{[\mathrm{I}][\mathrm{R}]}{[\mathrm{IR}]}[\mathrm{I}] \approx I_{\mathrm{tot}}
\end{gathered}
$$

The total concentration of the active site, $\mathrm{B}_{\max }$, is expressed in eq 9:

$$
B_{\max }=[\mathrm{R}]+[\mathrm{IR}]+[\mathrm{LR}]=\left(1+\frac{[\mathrm{L}]}{K_{\mathrm{d}}}+\frac{[\mathrm{I}]}{K_{\mathrm{i}}}\right)[\mathrm{R}]
$$


The relationship between the relative concentration of the bound conformer and the $I_{50}$ values, eq 11 can be obtained using the Cheng-Prusoff equation, ${ }^{26}$ eq 10 :

$$
\begin{gathered}
I_{50}=K_{\mathrm{I}}\left(1+\frac{[\mathrm{L}]}{K_{\mathrm{d}}}\right) \\
\frac{[\mathrm{IR}]}{I_{\text {tot }}}=\frac{[\mathrm{IR}]}{I_{0}}=\frac{I_{50}[\mathrm{R}]}{I_{50} K_{I}}=\frac{B_{\max }}{\left(1+\frac{[\mathrm{L}]}{K_{\mathrm{d}}}\right) K_{\mathrm{I}}+I_{50}}=\frac{B_{\max }}{2 I_{50}}=\frac{\Theta}{I_{50}}
\end{gathered}
$$

where

$$
\Theta=\frac{B_{\max }}{2}
$$

$\Theta$ values, as defined in eq 11 , can be kept constant during the experimental study; thus, they can be canceled out during the correlation between the library members (eq 6). The term $1 / I_{50}$ is referred in the following as binding activity. Combining eqs 6 and 11 leads to eq 12 .

$$
\frac{\left[\mathrm{I}_{50}^{j}\right]}{\left[\mathrm{I}_{50}^{i}\right]}=\frac{\frac{f^{i}}{n^{i}}}{\frac{f^{j}}{n^{j}}} \Rightarrow \frac{1}{\left[\mathrm{I}_{50}\right]} \propto \frac{f_{\mathrm{BC}}}{n_{\text {traj }}}
$$

Generally, we can conclude that for every member of a suitable molecular library, the probability of the binding conformation of the CORE in the unbound environment is a linear function, with positive slope, of the binding activity. On the other hand it has to be emphasized that the bound conformation rarely coincides the lowest energy conformer in the unbound state in solution. The number of rotable bonds of the ligand primarily influences the strain energy as it was demonstrated on several large scale studies ${ }^{27,28}$ on pharmaceutically relevant protein-ligand crystal complexes. The term strain energy was used to the energy difference between the lowest energy conformer in solution and the energy of the conformation in the bound state. In these studies, not surprisingly, correlation between bioactivity and the conformational flexibility was not perceived while the $\Delta G_{\text {bind }}$ values varied for the molecules. According to the general observation the flexible ligands tend to bind in extended conformation, however a number of exceptions as well as "maximally compact arrangements" was also reported. ${ }^{29}$

In summary, the bioactive conformation does not necessary prevail in the unbound state and "only" eq 12 should stand in a specially designed library. A computational procedure was developed, based on this equation, to locate the binding conformation in the conformational ensemble in solution.

\section{Results and Discussion}

Synthesis and Characterization of A $\beta$-Epitope Peptides Containing Flanking Sequences. The application of short linear peptides as antigens has some well-known limitations, a major drawback being the rapid proteolytic degradation in vivo. The incorporation of nonproteinogenic amino acids such as $\beta$-Ala ${ }^{30}$ or of D-amino acids ${ }^{31,32}$ is capable of providing protection from proteolytic digestion. Another frequent problem of linear peptides, namely their flexibility which may limit the presentation of binding conformations, has been shown to be overcome by restricting peptide mobility through cyclization. ${ }^{33-36}$ However, cyclic peptides with small ring size might have low antigenicity as compared to their linear versions. ${ }^{37}$ Furthermore, the nature of the bonds introduced for cyclization might also affect the antibody recognition, and a fairly rigid amide bond between $N$ - and $C$-terminal may abolish the access to a binding conformation. On the other hand, cyclic peptides containing disulfide bridge have been shown to yield higher antigenicity than the linear peptides. ${ }^{38}$

Based on these previous findings, the influence of $\alpha-\mathrm{L}-, \beta$ and $\alpha$-D-alanine flanking regions on antibody binding and conformational flexibility was studied by the application of linear and cyclic peptide analogs of the $\beta$-amyloid(4-10) epitope sequence. Cyclization via disulfide bridge formation was performed by dissolving the peptides in $50 \mathrm{mM}$ aqueous ammonium acetate, $\mathrm{pH}$ 6: dimethyl sulfoxide, 1:1 (v/v), and the reaction was carried out at $25^{\circ} \mathrm{C}$ for $24 \mathrm{~h}$. In order to avoid oligomerization of linear precursors, reactions were generally performed at low peptide concentrations $(0.2 \mathrm{mg} / \mathrm{mL})$. The cyclic products (as well as linear peptides) were characterized by analytical HPLC and mass spectrometry, which ascertained high purities and correct structures for all peptide derivatives (Table 1 and Figure 1).

The Effect of Flanking Sequences on Antibody Binding of Linear and Cyclic Peptides. Linear and cyclic peptides comprising the $\beta$-amyloid(4-10) epitope were compared for binding to an anti-A $\beta(1-17)$ monoclonal antibody by indirect enzyme-linked immunosorbent assay (ELISA). In order to overcome the drawbacks associated with the direct adsorption of small peptides to coating surfaces due to differential coating properties and possible conformational changes of the epitope, ${ }^{39}$ the peptides were attached to the surface of the ELISA plate using the biotin-streptavidin interaction. To this purpose, a pentaglycine spacer was introduced at the $N$-terminus of the peptides in order to preserve the peptide conformation and improve the epitope accessibility. Based on the ELISA data (Table 1, Figures 2 and 3), the effects of cyclization and/or flanking regions adjacent to the B-cell epitope on the antibody binding could be reproducibly assessed.

The cyclization of $\mathrm{A} \beta(4-10)$ epitope (16) resulted in a reduced antibody binding compared to the linear peptide (1), while the reverse sequence did not show any affinity to the monoclonal antibody (mAb) (Table 1). Interestingly, the addition of two and three $\alpha$-L-alanine residues as flanking sequences to the epitope led to substantially increased binding to the antibody, both with the linear and cyclic antigens. The highest binding was obtained for the linear peptide $\mathbf{3}$ in which the epitope was flanked by two $\alpha$-L-alanine residues, as compared to peptide $\mathbf{6}$ (epitope flanked by $\alpha$-L-alanine trimers) and peptides $\mathbf{4}$ and $\mathbf{5}$ which contained $\beta$ - or $\alpha$-D-alanine flanking dimers (Figure 2 and Table 1).

Binding data for the cyclic peptides to the mAb are compared in Figure 3. All peptides containing the $A \beta(4-10)$ epitope with alanine dimer or trimer showed high binding to the $\mathrm{mAb}$, compared to the cyclic peptide $\mathbf{1 6}$ without flanks. No significant differences in the antibody binding were determined for the cyclic peptides containing two or three $\alpha$-L-alanine or $\beta$-alanine residues. However, these peptides showed higher antigenicity than the cyclic peptides $\mathbf{1 9}$ and $\mathbf{2 2}$ in which the epitope was flanked by $\alpha$-D-alanine dimers or trimers.

Effect of Flanking Sequences on the Conformation of Linear and Cyclic Epitope Peptides Determined by Circular Dichroism (CD) Spectroscopy. The conformational preferences of linear and cyclic peptides containing the $\mathrm{A} \beta(4-10)$ epitope flanked by $\alpha-\mathrm{L}-, \beta$-, or $\alpha$-D-alanine dimers or trimers at both $N$ - and $C$-terminus were studied by CD spectroscopy. Spectra were recorded in water and in $100 \%$ TFE, since the latter solvent 
Table 1. Characteristics of $\mathrm{A} \beta(4-10)$ Epitope Peptides

\begin{tabular}{|c|c|c|c|c|}
\hline peptide no. & sequence $^{a}$ & $\mathrm{HPLC} \mathrm{R}_{\mathrm{t}}(\mathrm{min})^{b-d}$ & {$[\mathrm{M}]$ calcd/found $^{e, f}$} & $c\left(\times 10^{-8} \mathrm{~mol} / \mathrm{L}\right)^{g}$ \\
\hline 1 & biotin-GGGGGFRHDSGY-NH & 24.80 & $1390.5837 / 1390.5755$ & $1.10 \pm 0.12$ \\
\hline 2 & biotin-GGGGGYGSDHRF-NH ${ }_{2}$ & 25.16 & $1390.5837 / 1390.5792$ & \\
\hline 3 & biotin-GGGGGAAFRHDSGYAA-NH ${ }_{2}$ & 25.26 & $1674.7321 / 1674.7292$ & $0.52 \pm 0.11$ \\
\hline 5 & biotin-GGGGGaaFRHDSGYaa-NH ${ }_{2}$ & 25.32 & $1674.7321 / 1674.7285$ & $0.92 \pm 0.22$ \\
\hline 6 & biotin-GGGGGAAAFRHDSGYAAA- $\mathrm{NH}_{2}$ & 25.42 & $1816.8063 / 1816.8089$ & $0.70 \pm 0.16$ \\
\hline 7 & biotin-GGGGG $\beta \mathrm{A} \beta \mathrm{A} \beta \mathrm{AFRHDSGY} \beta \mathrm{A} \beta \mathrm{A} \beta \mathrm{A}-\mathrm{NH}_{2}$ & 24.17 & $1816.8063 / 1816.8133$ & $1.14 \pm 0.01$ \\
\hline 8 & biotin-GGGGGaaaFRHDSGYaaa-NH $\mathrm{N}_{2}$ & 25.41 & $1816.8063 / 1816.8001$ & $0.82 \pm 0.20$ \\
\hline 11 & biotin-GGGGGC $\beta$ A $\beta$ AFRHDSGY $\beta \mathrm{A} \beta$ AC-NH ${ }_{2}$ & 25.47 & $1880.7505 / 1880.7459$ & n.a. \\
\hline 12 & biotin-GGGGGCaaFRHDSGYaaC-NH $\mathrm{N}_{2}$ & 27.08 & $1880.7505 / 1880.7455$ & n.a. \\
\hline 13 & biotin-GGGGGCAAAFRHDSGYAAAC-NH ${ }_{2}$ & 28.06 & $2022.8247 / 2022.8350$ & n.a. \\
\hline 14 & biotin-GGGGGC $\beta \mathrm{A} \beta \mathrm{A} \beta \mathrm{AFRHDSGY} \beta \mathrm{A} \beta \mathrm{A} \beta \mathrm{AC}-\mathrm{NH}_{2}$ & 25.11 & $2022.8247 / 2022.8197$ & n.a. \\
\hline 15 & biotin-GGGGGCaaaFRHDSGYaaaC-NH ${ }_{2}$ & 25.51 & $2022.8247 / 2022.8218$ & n.a. \\
\hline 16 & biotin-GGGGG[CFRHDSGYC]-NH 2 & 25.37 & $1594.5863 / 1594.5868$ & $2.28 \pm 0.01$ \\
\hline 22 & biotin-GGGGG[CaaaFRHDSGYaaaC]-NH ${ }_{2}$ & 25.11 & $2020.8090 / 2020.8023$ & $1.11 \pm 0.29$ \\
\hline 23 & Ac-FRHDSGY- $\mathrm{NH}_{2}$ & 21.19 & $921.4 / 921.8$ & n.a. \\
\hline 24 & Ac-AAFRHDSGYAA-NH 2 & 21.83 & $1205.5 / 1205.8$ & n.a. \\
\hline 25 & Ac-[CFRHDSGYC]- $\mathrm{NH}_{2}$ & 22.37 & $1125.4 / 1125.5$ & n.a. \\
\hline 26 & Ac-[CAAFRHDSGYAAC]- $\mathrm{NH}_{2}$ & 23.39 & $1409.5 / 1409.7$ & n.a. \\
\hline
\end{tabular}

${ }^{a}$ Cyclopeptide sequences are indicated by brackets; lower case aa denotes D-amino acids. ${ }^{b}$ Peptides 1-22, RP-HPLC column: Nucleosil 300-7 $\mathrm{C}_{18}$ column. ${ }^{c}$ Peptides 23-26, RP-HPLC column: Discovery BIO Wide Pore $\mathrm{C}_{18}$, Supelco. ${ }^{d}$ The purity of all compounds was $>95 \%$ according to the HPLC calculated from AUCs (area under the curves). ${ }^{e}[\mathrm{M}]$, peptides 1-22, mass spectrometric analysis was performed with a Bruker APEX II FTICR instrument. ${ }^{f}$ Peptides 23-26, mass spectrometric analysis was performed with a Bruker Biflex linear TOF mass spectrometer. ${ }^{g}$ The peptide concentration to obtain an $\mathrm{OD}=1.0$ in ELISA experiments. ${ }^{h}$ n.a.: not analyzed.

A.

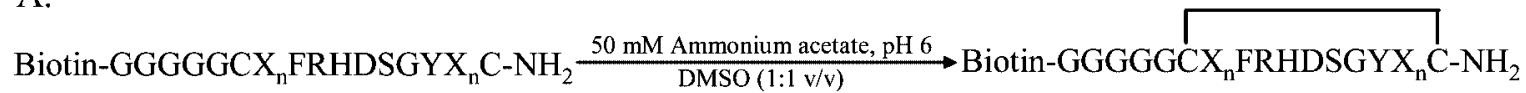
(where $\mathrm{X}=$ Ala, D-Ala, $\beta$-Ala and $\mathrm{n}=2,3$ )

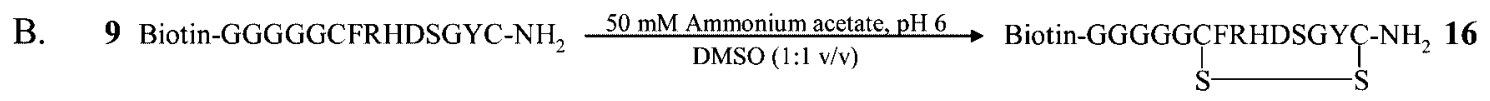

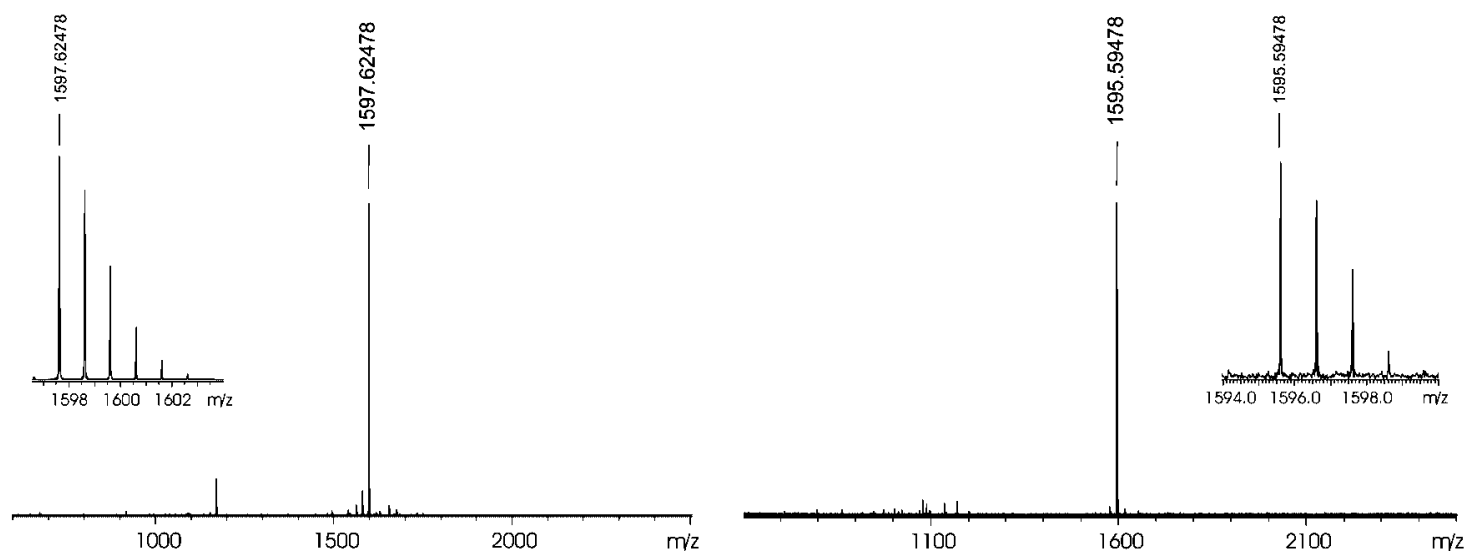

Figure 1. Outline of the synthesis of cyclic peptides containing the A $\beta(4-10)$ epitope (A) and MALDI-FTICR mass spectra of linear peptide (9) and its cyclic version (16).

is well-known to preferentially stabilize peptides and proteins in an ordered conformation. ${ }^{40-42}$ The CD spectra of peptides 3-8 and 17-22 are influenced by the chiral contribution of aromatic residues (Phe, His, and Tyr) in addition to the CD of the backbone conformation (Figure 4). The spectra of peptides $5,8,19$, and 22 also reflect the chiral and conformational effects 

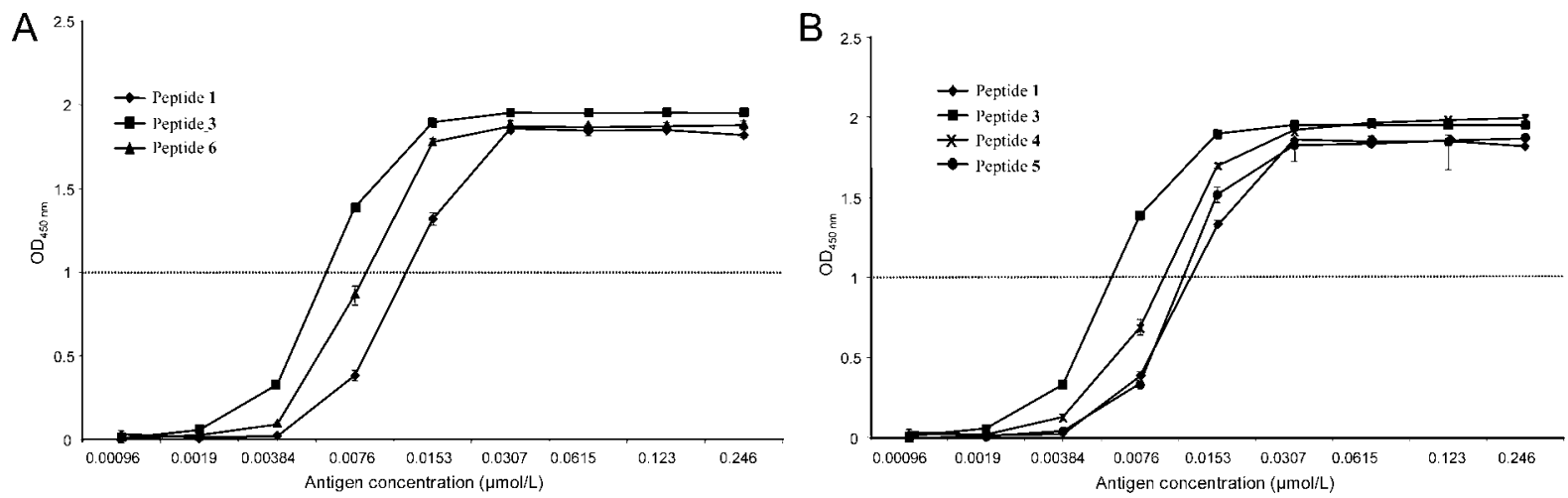

Figure 2. Binding of mouse anti- $\mathrm{A} \beta(1-17) \mathrm{mAb}$ to linear $\mathrm{A} \beta(4-10)$ containing epitope peptides: (A) comparison of the length of Ala-flanking regions (peptides $\mathbf{1}, \mathbf{3}$, and $\mathbf{6}$ ); (B) comparison of the type of the Ala-flanking regions (peptides $\mathbf{1}, \mathbf{3}, \mathbf{4}$, and $\mathbf{5}$ ).
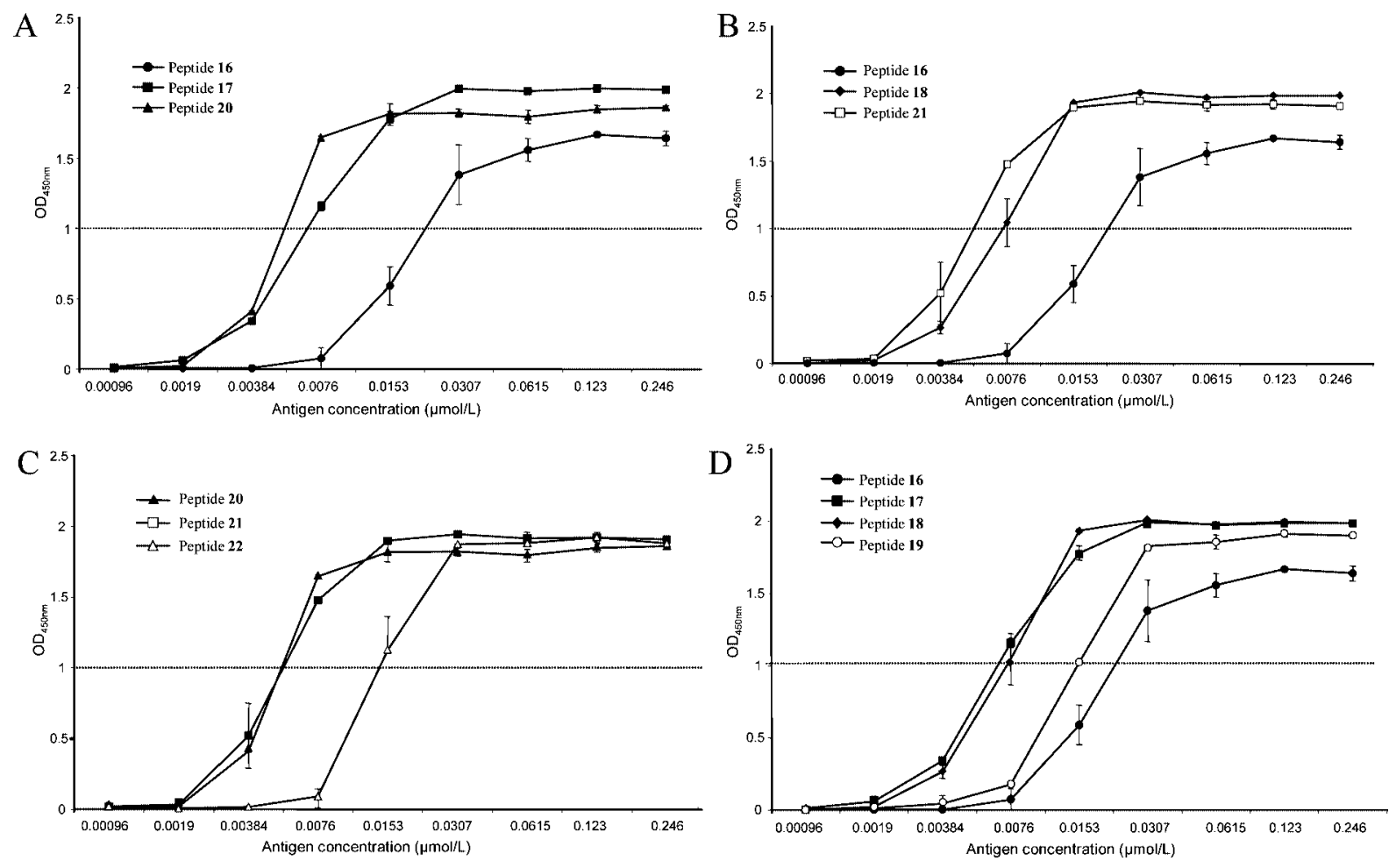

Figure 3. Binding of mouse anti-A $\beta(1-17) \mathrm{mAb}$ to cyclic peptides containing the $\mathrm{A} \beta(4-10)$ epitope. Comparative studies of the length of Alaflanking regions (peptides 16, 17, and 20) (A) or $\beta$-Ala flank regions (peptides 18 and 21) (B) and of the type of the amino acid in the flanks (peptides 20-22) (C) and (peptides 16-19) (D).

of D-alanine residues. Cyclic disulfides 17-22 are expected to adopt one major, rigid conformation but the spectral contribution of the chiral disulfide linkage must be also taken into consideration. The conformational effect of achiral $\beta$-alanine residues in peptides $\mathbf{4}, \mathbf{7}, \mathbf{1 8}$, and $\mathbf{2 1}$ is difficult to be evaluated. These spectra are similar to those of the linear and cyclic compounds without flanks (data not shown). In consequence, the CD spectra of the presented peptides (3-8 and $\mathbf{1 7 - 2 2})$ must be analyzed with extreme caution.

CD spectra of linear peptides in which the $\mathrm{A} \beta(4-10)$ epitope was flanked by $\alpha$-L-alanine dimers or trimers $(3,6)$ in water showed a weak positive band or shoulder near $220 \mathrm{~nm}$ and an intensive negative band at 198-199 nm, indicating the predominance of unordered structure (Figure 4A). ${ }^{43}$ Based on their spectral features, the peptides 3, 6, 17, 20 adopt an ordered, most probably folded (turn) conformation in TFE $\left(\pi-\pi^{*}\right.$ band at $207 \mathrm{~nm}$ and $\mathrm{n}-\pi^{*}$ band at $222-223 \mathrm{~nm}$ ) (Figure 4B). ${ }^{43-45}$

$\mathrm{CD}$ spectra of the linear and cyclic peptides in which the $\mathrm{A} \beta(4-10)$ epitope were flanked by $\alpha$-D-alanine dimers or trimers
$(5,8,19$, and 22) showed in water both the chiroptical and conformational effect of the D-amino acid residues (intensive positive band near 196-198 nm and a weaker positive band around 224-226 nm, Figure 4C). ${ }^{46}$ Compared to the spectra in water, the CD of peptides $\mathbf{5}, \mathbf{8}, \mathbf{1 9}$, and $\mathbf{2 2}$ recorded in TFE did not indicate any significant conformational changes (Figure 4D).

CD spectra of linear and cyclic peptides in which the $\mathrm{A} \beta(4-10)$ epitope was flanked by $\beta$-alanine dimers or trimers $(4,7,18$, and 21$)$ showed in water a positive band near 220 $\mathrm{nm}$, and a negative one around $200 \mathrm{~nm}$ (Figure 4E). ${ }^{47}$ According to Woody, peptides lacking a discernible regularity in their conformation might be expected to have weak and variable $\mathrm{CD}$ spectra. ${ }^{45} \mathrm{CD}$ spectra recorded in TFE reflect major conformational changes; a positive band near $192 \mathrm{~nm}$, a negative band at about $205 \mathrm{~nm}$ and a weak negative shoulder around $220 \mathrm{~nm}$. All these features indicate the presence of ordered conformer population(s) (Figure 4F).

NMR Solution Structure. Although the CD spectra recorded in water indicated the lack of a well defined structure, the 

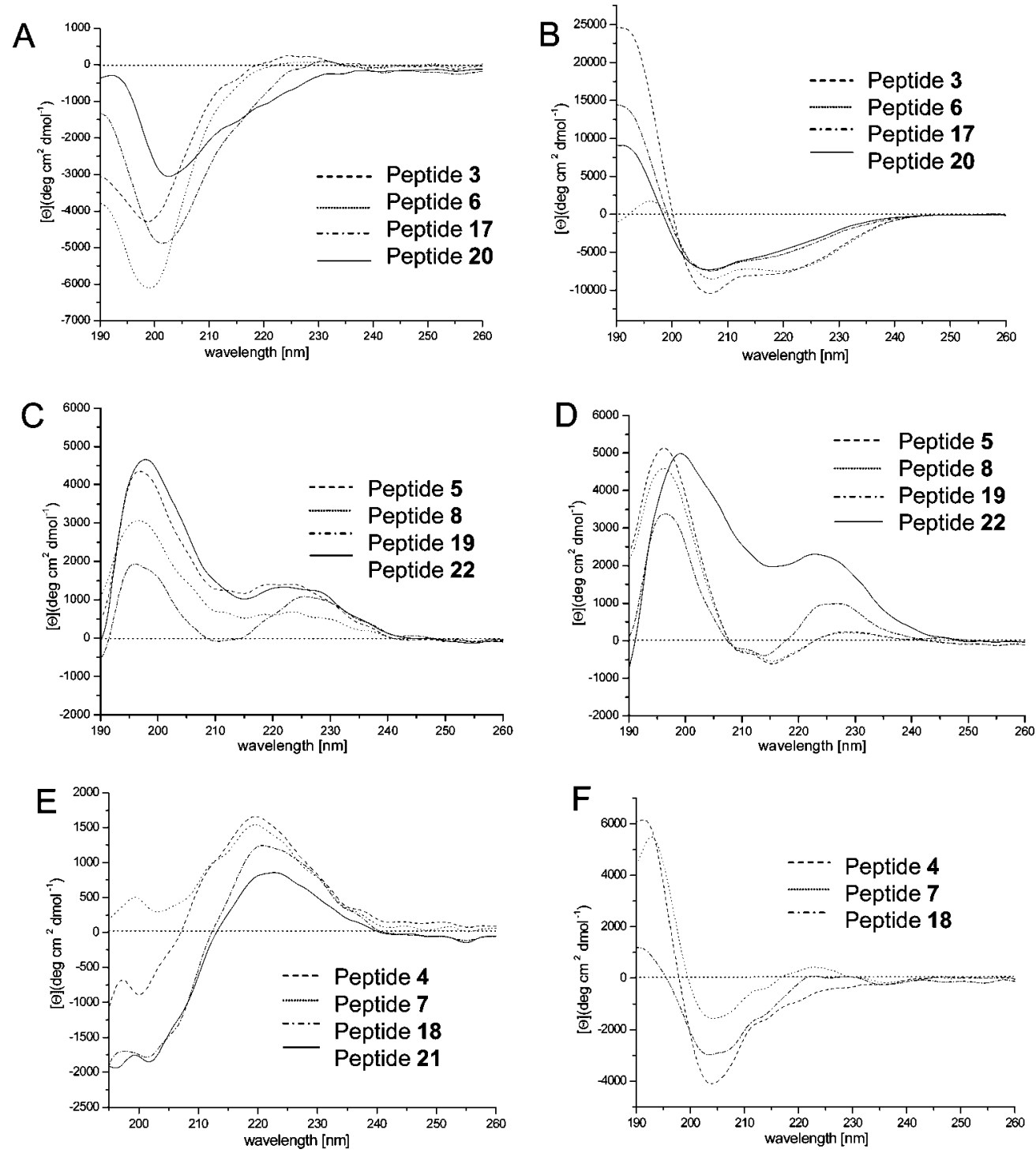

Figure 4. CD spectra of linear and cyclic $\beta$-amyloid(4-10)-containing epitope peptides in water and in TFE. Linear peptides flanked by $\alpha$-L-Ala dimers $(\mathbf{3})$ or trimers $(\mathbf{6})$ and their cyclic analogues $(\mathbf{1 7}$ and $\mathbf{2 0})$ : (A) in water, (B) in TFE. Liner peptides flanked by $\alpha$-D-Ala dimers $(\mathbf{5})$ or trimers (8) and their cyclic analogues (19 and 22): (C) in water, (D) in TFE. Linear peptides flanked by $\beta$-Ala dimers (4) or trimers (7) and their cyclic analogues (18 and 21): (E) in water, (F) in TFE.

peptides might adopt a stable structure that can be defined by the NMR parameters. ${ }^{48}$ To investigate this, four peptides (two linear and two cyclic compounds) were selected for NMR measurements based on their binding properties (low antigenicity: peptides 1 and 16; high antigenicity: peptides 3 and 17). Therefore, peptides 23-26 were synthesized without the pentaglycine spacer and biotin that were required for ELISA binding studies.

Their solution structure was determined by one- and twodimensional ${ }^{1} \mathrm{H}-{ }^{1} \mathrm{H}$ correlated TOCSY, NOESY, and ROESY ${ }^{1} \mathrm{H}$ NMR measurements.

For all four peptides studied NOESY measurements showed no cross-peaks at $300 \mathrm{~K}$. Thus, in the case of peptide $\mathbf{2 5}$, which is the smallest cyclic peptide and might have the most rigid structure, ROESY spectra were collected at $285 \mathrm{~K}$. In this case, sequential assignment was possible (Figure 5). In the fingerprint region, only sequential $(i, i+1)$ NOEs were detected between backbone $\mathrm{NH}$ and the side chain $\mathrm{H} \alpha$. Sequential NH-NH cross peaks occurred between Phe1-Arg2, Arg2-His3, Asp4-Ser5, Ser5-Gly6, Tyr7-Cys8. No long-range $i$ to $i+2$, or $i$ to $i+3$ NOEs were detected. All these data indicate that a high number

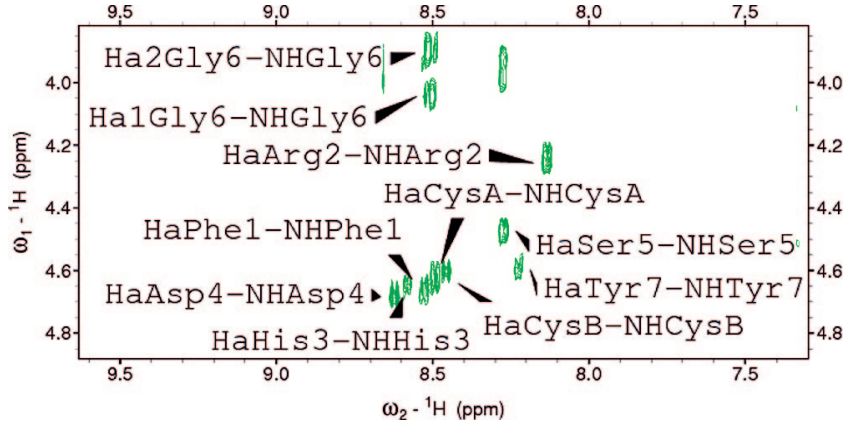

Figure 5. Part of the $2 \mathrm{D}{ }^{1} \mathrm{H}-{ }^{1} \mathrm{H}$ TOCSY spectra of peptide 25 with $60 \mathrm{~ms}$ mixing time. Peak assignment in the $\mathrm{NH}-\mathrm{H} \alpha$ region is shown.

of interchanging conformers are present in solution and it is not possible to determine a definite solution structure.

The one-dimensional ${ }^{1} \mathrm{H}$ spectra showed only a few overlaps in the $\mathrm{NH}$ region; therefore, direct detection of ${ }^{3} J_{\mathrm{NHH} \alpha}$ values was possible. In all cases, these values were between 6 and 7 $\mathrm{Hz}$, in accordance with mostly random coil solution structure. 
Scheme 1. Generation of the Conformational Ensemble for Each Peptide $(\mathrm{a}-\mathrm{d})$ and Selection of the Binding Conformation $(\mathrm{e}-\mathrm{g})^{a}$
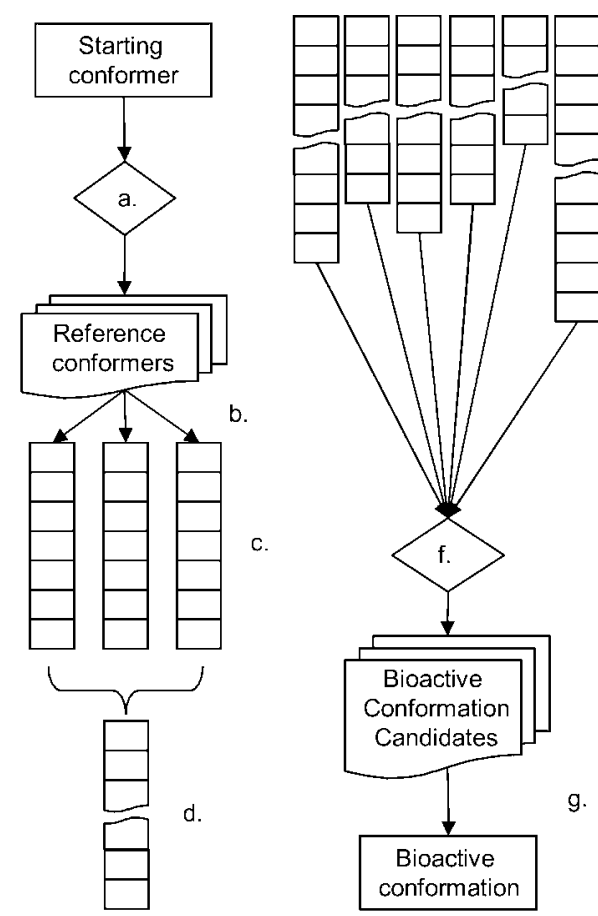

e.

${ }^{a}$ Key: (a) reference conformer generation; (b) molecular dynamics simulations; (c) trajectories; (d) concatenated trajectory for a single peptide; (e) concatenated trajectories for all peptides; (f) BC search algorithm; (g) nomination of prevailing candidates to binding conformations.

Temperature dependence studies at 285, 300, and $310 \mathrm{~K}$ of the chemical shifts for individual NH protons from onedimensional spectra were performed for peptide 25. For three well defined residues Arg2, Ser5, and Tyr7 the calculated $\Delta \delta /$ $\Delta T$ values were $-6.7,-6.2$, and $-5.7 \mathrm{ppb} /{ }^{\circ} \mathrm{C}$, respectively. These values might suggest that the backbone amide protons are somehow protected from exchange with solvent; however, as the values are closed to $-7 \mathrm{ppb} /{ }^{\circ} \mathrm{C}$, these tend more to be in random coil.

Computational Methods. The conformational ensembles of the molecules were obtained computationally (Scheme 1a-d). To develop starting conformers (RCs, reference conformers) for the subsequent molecular dynamics simulations a conformational search $^{24}$ was applied for each peptide. The conformational search operates on a stochastic basis by using high energy molecular dynamics simulations where no solvent effect is taken into account. Geometry optimization procedures are performed on the trajectory steps depending on the conformational change. The RCs are selected from the low energy conformers so that the conformational diversity between each other should not be lower than a specified limit. The vector of backbone $\varphi$ and $\Psi$ dihedral angles of the CORE defined the conformational space, while the deviation was computed as the root-mean-square deviation (rmsd) of the corresponding dihedral vectors. The search proceeds until no new conformer is found. This type of conformational analysis was applied both on cyclic and on linear molecules. The more RCs the molecule has, the more expanded its accessible conformational space is. Therefore, the number of RCs can be used as a flexibility measure of the molecule.

MD simulations in aqueous environment and at room temperature and pressure were launched from all RCs of all peptides (Scheme 1c). The reasoning behind using more starting conformers for one peptide is that single MD may not reach

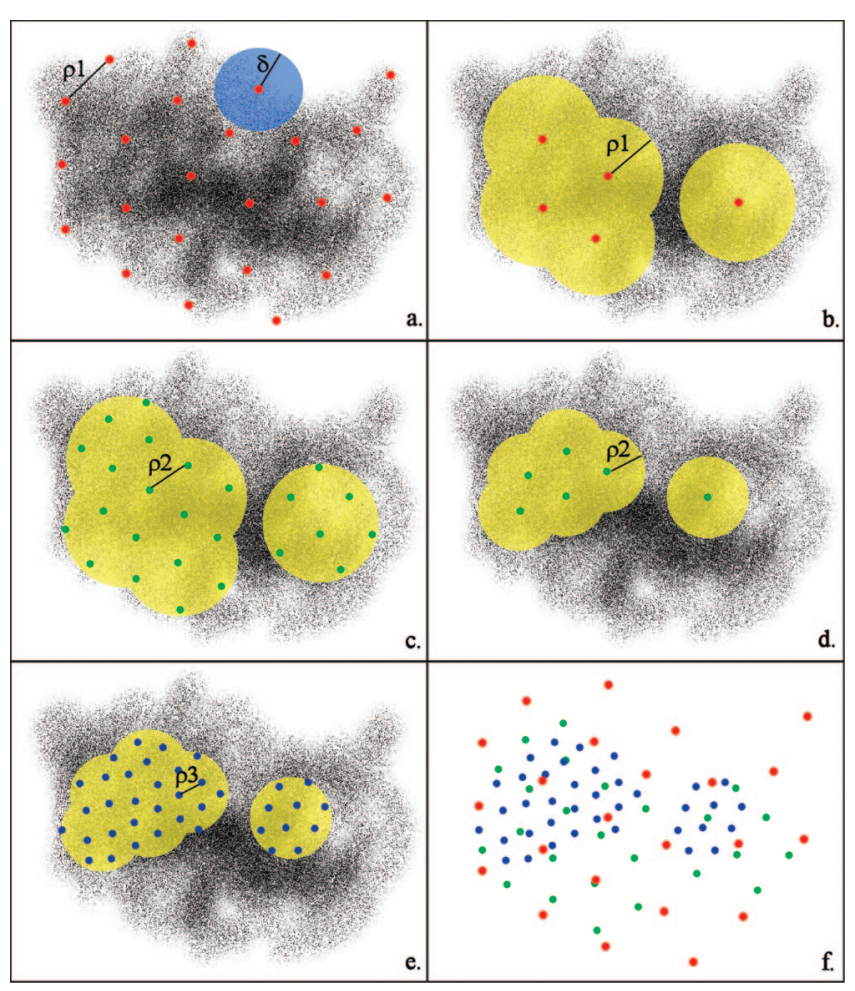

Figure 6. Progress of the binding conformation search algorithm. Three cycles in a schematic 2D conformational space are shown. The fuzzy gray background represents the visited points by the trajectories of all molecules. (a) Collect anchor conformations, shown as red dots. These ACs cannot be closer to each other than $\rho 1$. Conformational density values are assigned to each anchor; one representative is shown in blue. (b) Select the best ACs by $q^{2}$, where $r>0$. The local environment of the selected ACs is marked in yellow. (c) Remap the selected subspace with new ACs (green) using the new limit $\rho 2$. These anchors are also filtered by their correlation quality. (d) The new subspace is shown in yellow. (e) This subspace is also populated with much denser ACs. (f) The AC, selected from the whole set of previously collected ACs is nominated as the binding conformation candidate of this run which has the best $q^{2}$.

the whole conformational space of a flexible peptide within the simulation time.

The probabilities of the BCs in the simulated trajectories and the binding activities have a linear correlation with positive slope and it enables us to locate regions of BCs. The whole process of seeking the $\mathrm{BC}$ is shown in Scheme $1 \mathrm{e}-\mathrm{g}$.

Our novel algorithm ${ }^{24}$ was utilized to search for these regions in the CORE space. The CORE space can be represented by selected dihedrals of the CORE or simply by the Cartesian coordinates of the CORE atoms. In the first case, the conformational diversity is computed as the rmsd of the dihedral vectors, while in the second case it is given as the rmsd of the atomic positions of the superimposed structures. ${ }^{49}$

The BC search algorithm (Scheme 1f) can locate regions that have positive Pearson correlation coefficient $(r)$ and high enough cross-validated $r^{2}\left(q^{2}\right)$ value. The operation of this algorithm, in an arbitrary, two-dimensional CORE conformational space, is summarized in Figure 6.

The process starts with collecting anchor conformations (ACs) from trajectories of all molecules (Scheme 1e). These conformations cannot be closer to each other than $\rho_{1}$, a user defined limit (Figure 6a). A conformational density array is assigned to each AC. The number of components of this array is the number of molecules. The algorithm goes through again on the trajectories, and develops density values for each AC. The blue circle in 

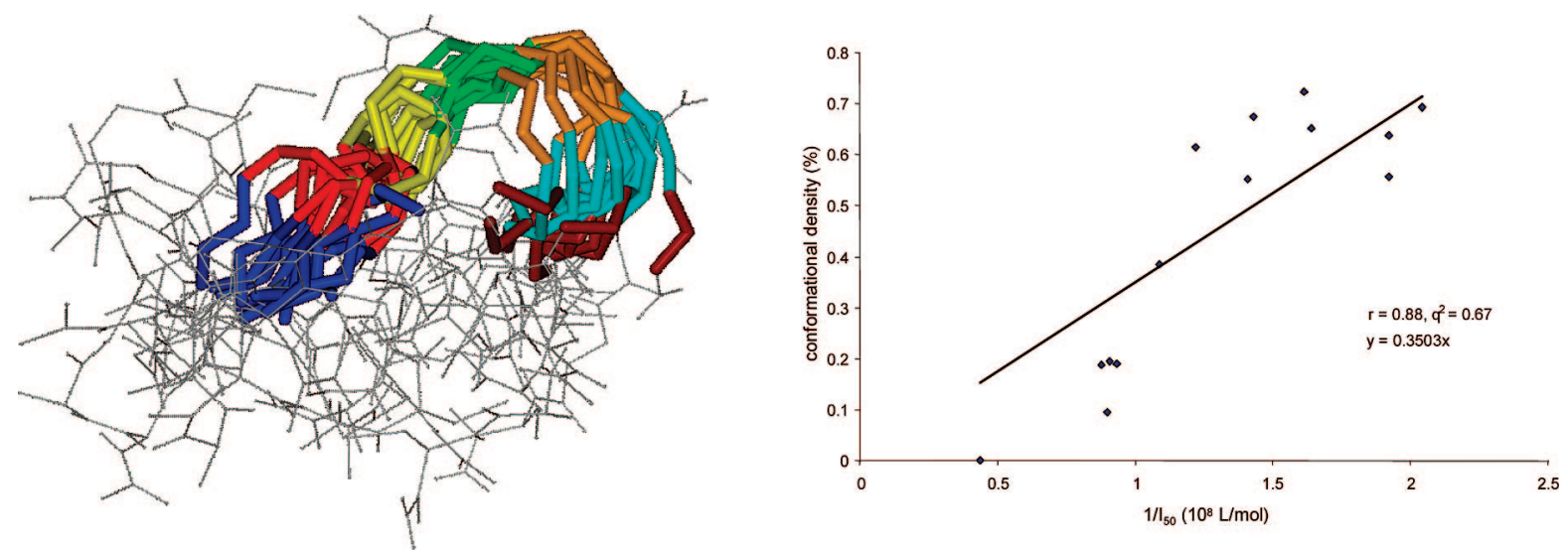

Figure 7. Binding conformation of the 14 epitope peptides, superimposed by their CORE, the backbone atoms of the FRHDSGY region. The amino acids F, R, H, D, S, G, and Y are marked in blue, red yellow, green, orange, cyan, and brown, respectively; only the backbone is shown. The off-CORE part of the peptides is marked in gray. Conformational density-activity curve for the BC is shown on the right. The horizontal axis represents the binding activity for each peptide; on the vertical axis is shown the percentage of the given $\mathrm{BC}$ in the full conformational ensemble of the peptide in question.

Table 2. Relative Antibody Binding and the Density of the Binding Conformation in the Full Sampled Space for a Given Peptide

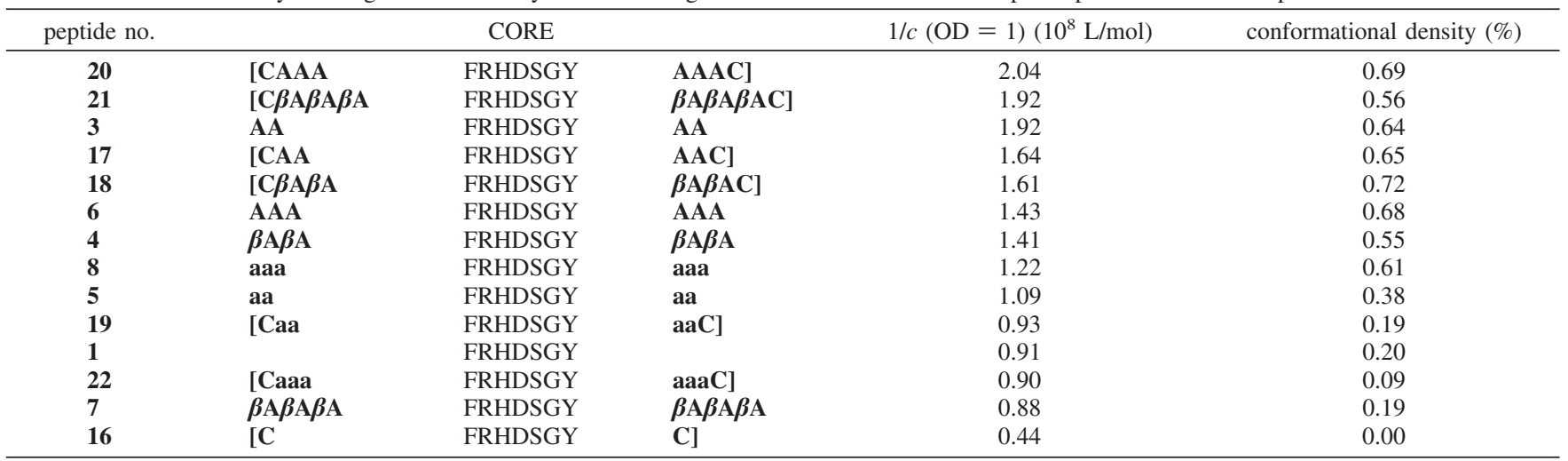

Figure 6a symbolizes the threshold, $\delta$, for the density calculation, which is kept constant during the whole run. The threshold was applied in the current study as a simple cutoff, however, Gaussian weighting is optionally available in our implementation. The $q^{2}$ and $r$ values are evaluated for all ACs using their density arrays and the binding activities. Those ACs are selected that has positive $r$ and high enough $q^{2}$ value.

The region that is closer to the selected best ACs than $\rho_{1}$ (Figure 6b) is remapped with new, much densely populated ACs with a lower diversity limit, $\rho_{2}$ (Figure $6 \mathrm{c}$ ). Figure $6 \mathrm{~d}$ shows the ACs selected in this cycle and their environment to be remapped in the next turn (Figure 6e). The algorithm proceeds stepwise at decreasing $\rho$ values until the repeat count reaches the user defined limit $(N \rho)$. As the result of this type of calculation may depend on the sequence of conformations in the input trajectories (Scheme 1e), this algorithm is repeated $N_{\text {rand }}$ times on randomized sequences.

Those ACs that has high enough $q^{2}$ and positive $r$ values are clustered $^{50,51}$ according to their conformational diversity (Scheme $1 \mathrm{~g})$. The cluster, which has the best $q^{2}$ value, is accepted as the BCC. Two clusters were found, with $q^{2} 0.64$ and 0.67 and with $r 0.88$ for both. The latter was accepted as the binding conformation (Figure 7, Table 2). The significance of the model was validated via F-test $(F=31.09)$.

\section{Conclusion}

In the present study, the effect of non-native flanking sequences on antibody binding and conformational flexibility of linear and cyclic peptides containing the plaque-specific $\beta$-amyloid(4-10) epitope was investigated. Cyclization of the native $\mathrm{A} \beta(4-10)$ epitope resulted in substantially reduced antibody binding compared to its linear version. However, the unfavorable effect of cyclization was completely compensated by insertion of $\alpha$ - or $\beta$-alanine dimer or trimer at both $N$ - and $C$-terminus of the epitope in the respective cyclopeptides. Furthermore, we found that the chirality of $\alpha$-Ala residues had a marked influence on the antibody recognition. Cyclopeptides comprising the epitope flanked by $\alpha$-D-alanine had the lowest relative binding (compared to $\alpha$-L-alanine and $\beta$-alanine flanking regions); however, higher than the cyclic peptide without any flanks.

CD spectroscopy was applied to analyze the conformation of the epitope peptides. CD spectra of cyclic peptides in which the $\mathrm{A} \beta(4-10)$ epitope was flanked by $\alpha$-L-alanine dimers or trimers, recorded in water, indicated the presence of some ordered conformers as compared to those of the corresponding linear peptides. No significant effect of cyclization on the solution conformation of the peptides containing the epitope with $\alpha$-D-alanine or $\beta$-alanine flanks was determined in water. Linear and cyclic peptides comprising $\alpha$-L-alanine or $\beta$-alanine dimer and trimer flanks exhibited some ordered structure in TFE. In contrast, the conformation of linear and cyclic peptides with $\alpha$-D-alanine flanks did not show significant changes in TFE.

A linear relationship between the binding activity and the probability of the binding conformation in the solvent for a set of molecules allowed us to develop a novel 3D QSAR method 
exclusively for flexible molecules. The algorithm was coded in JAVA language using standard ChemAxon tools. This type of 3D QSAR application avoids using grids and multidimensional regression methods. We accepted the best model, with $q^{2}=$ 0.67 , as the binding conformation obtained from the calculations. According to this model the backbone of the examined FRHDSGY sequence adopts an extended conformation, with a turn like structure around serine. It has to be noted that other model candidates that had unacceptable $q^{2}$ values mostly adopted such globular conformations, where some of the side chains of the CORE amino acids were buried. On the other hand, in the case of the present accepted model the side chains are accessible to the target protein (antibody).

The conformational analysis suggests that the peptides with $\alpha$-D-Ala flanks have the less flexible core epitope regions and the $\beta$-Ala flanks result in increased flexibility. Comparing the antibody recognition of the peptides in which the epitope was flanked by $\alpha$-L-Ala and $\beta$-Ala residues, the cyclic peptides have slightly increased antibody binding compared with the linear ones. However, the differences are not significant except for the case of linear and cyclic epitope peptides containing three $\beta$-Ala in flanking regions. As presented in Table 2, according to the molecular dynamics simulations, the linear peptide has fairly low density of binding conformation compared with the cyclic analogue. In the case of the peptides with $\alpha$-D-Ala flanks or without flanks, the cyclic compounds have lower antibody binding compared to the linear ones, the cyclization of these peptides resulting in less favored and fairly rigid conformations.

The solution structure determined by NMR spectroscopy indicated that a high number of interchanging conformers were present in solution and it was not possible to determine a definite solution structure of the investigated peptides. The lack of NOE peaks means that the distance between the $\mathrm{H}$ atoms is higher than $6 \AA$. Based on the modeling results, all $i$ and $i+2, i+3$ distances were analyzed and the values were higher than $6 \AA$. Moreover, sequential distances below $6 \AA$ were those detected by NMR.

Taken together, these results indicate that by appropriate combination of cyclization and insertion of Ala-based flanking regions it is feasible to construct simple B-cell epitope peptides with improved antigenicity.

\section{Experimental Section}

Materials. All amino acid derivatives and NovaSyn TGR resin were purchased from NovaBiochem (Läufelfingen, Switzerland) and D-(+)-Biotin from Calbiochem (Darmstadt, Germany). Scavengers, coupling agents, and cleavage reagents (triethylsilane, 4-methylmorpholine (NMM), piperidine, 1,8-diazabicyclo[5.4.0]undec-7-ene (DBU), trifluoroacetic acid (TFA), diisopropylethylamine (DIEA), acetic anhydride $\left(\mathrm{Ac}_{2} \mathrm{O}\right)$ ) were obtained from Fluka (Buchs, Switzerland), benzotriazole-1-yloxytrispyrrolidinophosphonium hexafluorophosphate (PyBOP) was from NovaBiochem. Dimethylformamide (DMF) was purchased from Acros Organics (Geel, Belgium), while ethanol, tert-butyl methyl ether, and acetonitrile were from Riedel-deHäen (Seelze, Germany). Other reagents and solvents were of analytical grade or highest available purity.

Synthesis of Biotinylated Linear A $\boldsymbol{\beta}(4-10)$ Epitope Peptides. Peptides, biotin-GGGGGFRHDSGY-NH $\mathrm{NH}_{2}$ (1), biotin-GGGGGYGSDHRF-NH $\mathrm{N}_{2}$ (2), biotin-GGGGGAAFRHDSGYAA-NH $\mathrm{N}_{2}$ (3), biotinGGGGG $\beta$ A $\beta$ AFRHDSGY $\beta$ A $\beta$ A-NH ${ }_{2}$ (4), biotin-GGGGGaaFRHDSGYaa- $\mathrm{NH}_{2}(\mathbf{5})$, biotin-GGGGGAAAFRHDSGYAAA-NH $\mathrm{N}_{2}$ (6), biotinGGGGG $\beta \mathrm{A} \beta \mathrm{A} \beta \mathrm{AFRHDSGY} \beta \mathrm{A} \beta \mathrm{A} \beta \mathrm{A}-\mathrm{NH}_{2}$ (7), and biotinGGGGGaaaFRHDSGYaaa- $\mathrm{NH}_{2}(\mathbf{8})$ were synthesized on a NovaSyn TGR resin ( $0.23 \mathrm{mmol} / \mathrm{g}$ coupling capacity) by 9-fluorenylmethoxycarbonyl/tert-butyl $\left(\mathrm{Fmoc} /{ }^{t} \mathrm{Bu}\right)$ chemistry, using a semiautomated Peptide Synthesizer EPS-221 (ABIMED, Langenfeld,
Germany). The following side-chain protections of amino acid derivatives were employed: Fmoc-Tyr $\left({ }^{t} \mathrm{Bu}\right)-\mathrm{OH}, \mathrm{Fmoc}-\operatorname{Ser}\left({ }^{t} \mathrm{Bu}\right)$ $\mathrm{OH}$, Fmoc-Asp( $\left.\mathrm{O}^{t} \mathrm{Bu}\right)-\mathrm{OH}$, Fmoc-His(Trt)-OH and Fmoc-Arg(Pbf)$\mathrm{OH}$. The synthetic protocol was as follows: (i) DMF washing $(3 \times$ $1 \mathrm{~min}$ ); (ii) Fmoc deprotection for 15 min using 2\% DBU and 2\% piperidine in DMF; (iii) DMF washing $(6 \times 1 \mathrm{~min})$; (iv) coupling of 5 equiv of Fmoc amino acid/ PyBOP/NMM in DMF for 45 min; (v) DMF washing $(3 \times 1 \mathrm{~min})$. After completion of the synthesis, the $N$-terminus was biotinylated using 5 equiv of D-(+)-Biotin/ PyBOP/ NMM. The peptides were then cleaved from the resin at $25^{\circ} \mathrm{C}$ for $3 \mathrm{~h}$ using a mixture of TFA, triethylsilane, and deionized water (95: 2.5: 2.5, v/v/v). The crude products were precipitated with cold tert-butyl methyl ether, washed three times with diethyl ether and solubilized in 5\% aqueous acetic acid prior to freezedrying. The crude peptides were purified by reverse phase-high performance liquid chromatography (RP-HPLC) on a preparative $\mathrm{C}_{18}$ column. Purified peptides were analyzed by analytical RPHPLC, and peptide structures characterized by matrix assisted laser desorption ionization-Fourier transform ion cyclotron resonance mass spectrometry (MALDI-FTICR MS) (Table 1).

Synthesis of Biotinylated Cyclic A $\boldsymbol{\beta}(4-10)$ Epitope Peptides. Linear precursor peptides used for cyclization (biotin-GGGGGCFRHDSGYC-NH $\mathrm{N}_{2}$ (9), biotin-GGGGGCAAFRHDSGYAAC-NH (10) biotin-GGGGGC $\beta$ A $\beta$ AFRHDSGY $\beta$ A $\beta$ AC-NH $\mathrm{N}_{2}$ (11), biotinGGGGGCaaFRHDSGYaaC-NH 2 (12), biotin-GGGGGCAAAFRHDSGYAAAC-NH ${ }_{2}$ (13), biotin-GGGGGC $\beta$ A $\beta$ A $\beta$ AFRHDSGY$\beta \mathrm{A} \beta \mathrm{A} \beta \mathrm{AC}-\mathrm{NH}_{2}$ (14), and biotin-GGGGGCaaaFRHDSGYaaaC$\mathrm{NH}_{2}(\mathbf{1 5})$ ) were synthesized by SPPS using Fmoc/t'Bu chemistry according to the protocol described above. Trityl was used for the side-chain protection of cysteine. Prior to cyclization, the crude linear peptides were purified by preparative RP-HPLC, and purified peptides were characterized by analytical RP-HPLC and MALDIFTICR mass spectrometry (Table 1). All cyclization reactions were carried out by air oxidation in solution. Linear peptides containing two Cys residues were dissolved in a 1:1 (v/v) mixture of $50 \mathrm{mM}$ aqueous ammonium acetate $(\mathrm{pH} 6)$ and dimethyl sulfoxide at a peptide concentration of $0.2 \mathrm{mg} / \mathrm{mL}$, and then the reaction mixtures were stirred at $25{ }^{\circ} \mathrm{C}$ for $24 \mathrm{~h}$. After freeze-drying, the crude peptides $(\mathbf{1 6}-\mathbf{2 2})$ were purified by RP-HPLC on a preparative $\mathrm{C}_{18}$ column and characterized by analytical RP-HPLC and MALDIFTICR MS. Retention times and mass spectrometric data are presented in Table 1.

Synthesis of Linear and Cyclic A/(4-10) Epitope Peptides for NMR Studies. Linear and cyclic peptides Ac-FRHDSGY-NH (23), Ac-AAFRHDSGYAA-NH $\mathrm{N}_{2}$ (24), Ac-[CFRHDSGYC]- $\mathrm{NH}_{2}$ (25), and Ac-[CAAFRHDSGYAAC] $-\mathrm{NH}_{2}(\mathbf{2 6})$ were synthesized as described above with minor modifications. After completion of the synthesis, the $\mathrm{N}$-terminus was acetylated using a mixture of $\mathrm{Ac}_{2} \mathrm{O}(1 \mathrm{~mL})$, DIEA $(1 \mathrm{~mL})$ in DMF $(3 \mathrm{~mL})$ for $30 \mathrm{~min}$ at room temperature. The peptides were characterized by analytical RPHPLC and MALDI-TOF mass spectrometry (Table 1).

High-Performance Liquid Chromatography (HPLC). Analytical RP-HPLC was performed on a Bio-Rad instrument (BioRad Laboratories, Richmond, CA) using an analytical Nucleosil 300-7 $\mathrm{C}_{18}$ column $(250 \times 4 \mathrm{~mm}, 300 \AA$, $7 \mu \mathrm{m}$; Macherey-Nagel, Dueren, Germany) or Discovery BIO Wide Pore $\mathrm{C}_{18}$, Supelco (15 $\mathrm{cm} \times 4.6 \mathrm{~mm}, 3 \mu \mathrm{m})$ as a stationary phase. Linear gradient elution $(0 \min 0 \%$ B; 5 min $0 \%$ B; 50 min $90 \%$ B) with eluent A $(0.1 \%$ TFA in water) and eluent $\mathrm{B}(0.1 \%$ TFA in acetonitrile-water, $80: 20, \mathrm{v} / \mathrm{v}$ ) was used at a flow rate of $1 \mathrm{~mL} / \mathrm{min}$. Samples were dissolved in eluent A and the peptides detected at $220 \mathrm{~nm}$. Preparative purifications of linear and cyclic peptides were carried out on a Knauer HPLC system (Knauer, Berlin, Germany) using a preparative $\mathrm{C}_{18}$ column (GROM-SIL 120 ODS-4 HE, $10 \mu \mathrm{m}, 250$ × $20 \mathrm{~mm}$, pore size $120 \AA$; Grom, Herrenberg-Kayh, Germany). Linear gradient elution (0 min $10 \% \mathrm{~B} ; 5$ min $10 \% \mathrm{~B} ; 65 \mathrm{~min} 75 \%$ B) was employed using the same mobile phases as described above, with a flow rate of $10 \mathrm{~mL} / \mathrm{min}$. Peptides were dissolved in solvent $\mathrm{A}$, and the peak detection was performed at $220 \mathrm{~nm}$.

Mass Spectrometry (MS). MALDI-FTICR mass spectrometric analysis was performed with a Bruker APEX II FTICR instrument 
Table 3. Peptides Which Were Subjected to QSAR Analysis ${ }^{a}$

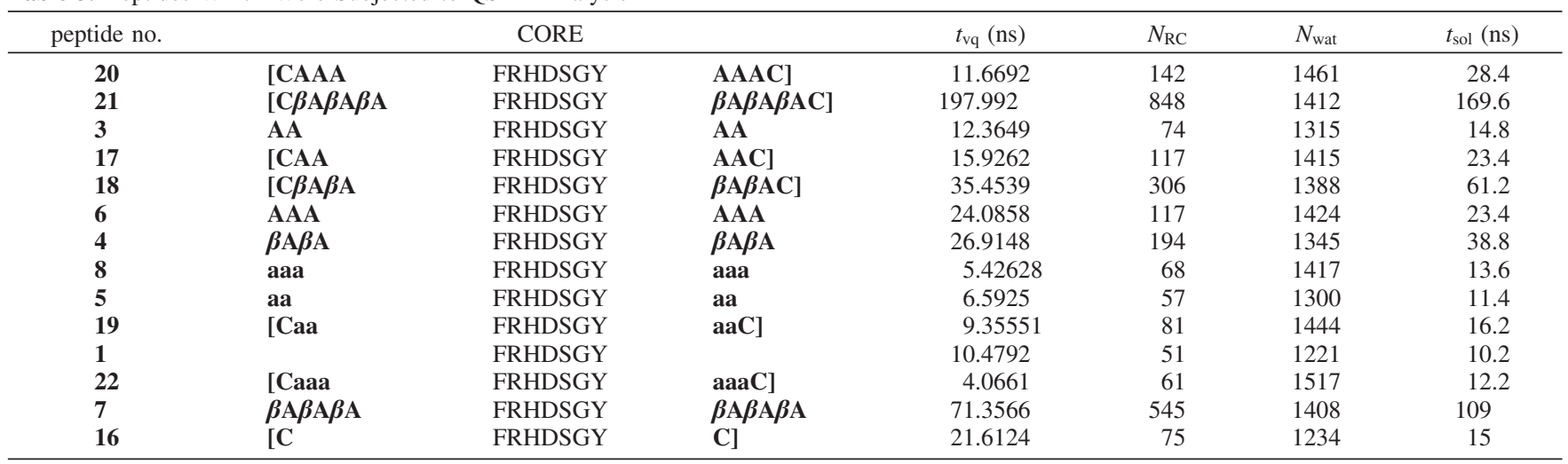

${ }^{a}$ The simulation time required by the conformational search $\left(t_{\mathrm{vq}}\right)$, the number of low energy conformers (NRC), the average number of water molecules $\left(N_{\text {wat }}\right)$ added to each peptide, and trajectory length subjected to data mining $\left(t_{\mathrm{sol}}\right)$ are shown. The peptides in the table are listed according to the increase of the antibody binding.

equipped with an actively shielded 7T superconducting magnet, a cylindrical infinity ICR analyzer cell, and an external Scout 100 fully automated X-Y target stage MALDI source with pulsed collision gas (Bruker Daltonics, Bremen, Germany). The pulsed MALDI nitrogen laser was operated at $337 \mathrm{~nm}$. A $100 \mu \mathrm{g} / \mu \mathrm{L}$ solution of 2,5-dihydroxybenzoic acid (DHB, Aldrich, Steinheim, Germany) in acetonitrile: $0.1 \%$ trifluoroacetic acid in water $(2: 1$, $\mathrm{v} / \mathrm{v})$ was used as the matrix. Aliquots of $0.5 \mu \mathrm{L}$ matrix solution and $0.5 \mu \mathrm{L}$ of sample solution were mixed on the stainless steel MALDI sample target and allowed to dry. Calibration was performed with a standard peptide mixture within an $\mathrm{m} / \mathrm{z}$ range of approximately 4000.

MALDI-TOF MS was carried out with a Bruker Biflex linear TOF mass spectrometer (Bruker Daltonics, Bremen, Germany). A saturated solution of $\alpha$-cyano-4-hydroxy-cinnamic acid (HCCA) in acetonitrile $/ 0.1 \%$ trifluoroacetic acid in water $(2: 1 \mathrm{v} / \mathrm{v})$ was used as the matrix. Acquisition of spectra was carried out at an acceleration voltage of $20 \mathrm{kV}$ and a detector voltage of $1.5 \mathrm{kV}$.

Enzyme-Linked Immunosorbent Assay (ELISA). Indirect ELISA analyses were performed using a standard dilution of the mouse anti-A $\beta(1-17)$ monoclonal antibody $(\mathrm{mAb})$ (clone 6E10, Chemicon, Temecula, CA) in combination with nine serial dilutions of the peptides. The dilutions were made in PBS solution containing $5 \mathrm{mM} \mathrm{Na} \mathrm{HPO}_{4}$ and $150 \mathrm{mM} \mathrm{NaCl}, \mathrm{pH}=7.5$. Ninety-six-well ELISA plates (BioRad, Hercules, CA) were coated with $100 \mu \mathrm{L} /$ well streptavidin solution (Sigma-Aldrich, Steinheim, Germany) in PBS $(2.5 \mu \mathrm{g} / \mathrm{mL})$ at $25{ }^{\circ} \mathrm{C}$ for $2 \mathrm{~h}$. After the wells were washed with PBS-T (0.05\% Tween-20 in PBS, pH 7.5), $100 \mu \mathrm{L} /$ well of biotinylated epitope peptides was added and the mixtures were incubated at $25{ }^{\circ} \mathrm{C}$ for $2 \mathrm{~h}$. The plates were washed four times with $200 \mu \mathrm{L} /$ well PBS-T, and the nonspecific adsorption sites were blocked with $5 \%$ BSA (w/v) in PBS, by incubation at $4{ }^{\circ} \mathrm{C}$ for $12 \mathrm{~h}$. Then, $100 \mu \mathrm{L} /$ well of the mouse anti-A $\beta(1-17)$ monoclonal antibody (1:4000 dilution in 5\% BSA) was added to each well. The plates were incubated at $25{ }^{\circ} \mathrm{C}$ for $2 \mathrm{~h}$ and then washed four times with washing buffer. A $100 \mu \mathrm{L}$ solution of peroxidase goat antimouse IgG (Jackson Immuno Research, West Grove, PA), diluted 5000 times in 5\% BSA, was added to each well and the plates incubated at $25{ }^{\circ} \mathrm{C}$ for two hours, then washed three times with washing buffer and two times with $0.05 \mathrm{M}$ sodium phosphate-citrate buffer, pH 5. A $100 \mu \mathrm{L}$ volume of $o$-phenylenediamine dihydrochloride (OPD) (Merck, Darmstadt, Germany) in phosphate-citrate substrate buffer at $1 \mathrm{mg} / \mathrm{mL}$ containing $2 \mu \mathrm{L}$ of $30 \%$ hydrogen-peroxide (Merck, Darmstadt, Germany) per $10 \mathrm{~mL}$ was added, and absorbance was measured at $450 \mathrm{~nm}$ on a Wallac 1420 Victor $^{2}$ ELISA Plate Counter (PerkinElmer, Boston, MA). The concentration of the peptide solution, which gave an $\mathrm{OD}_{450}$ of 1, was calculated, and data are presented in Table 1.

Circular Dichroism Spectroscopy (CD). Circular dichroism spectra were recorded on a JASCO spectropolarimeter, model J-715, at $20{ }^{\circ} \mathrm{C}$ in quartz cells of $0.05 \mathrm{~cm}$ path length, under constant nitrogen flush. The instrument was calibrated with $0.06 \%$ (w/v) ammonium- $d$-camphor-10-sulfonate (Katayama Chemical, Japan) in water. Distilled water and trifluoroethanol (TFE) (Fluka, Buchs, Switzerland) were used as solvents. The concentration of the samples was $200 \mu \mathrm{M}$. Spectra were averaged over six scans between 190 and $260 \mathrm{~nm}$. Results are expressed in terms of mean residue ellipticities $\left([\Theta]\right.$ in $\left.\operatorname{deg~} \mathrm{cm}^{2} \mathrm{dmol}^{-1}\right)$ after subtraction of the solvent baseline.

NMR Spectroscopy. Measurements were performed on a Bruker DRX $500 \mathrm{MHz}$ spectrometer equipped with a z-gradient $5 \mathrm{~mm}$ triple resonance probe head. Temperature values were checked with the 1,2-ethanediol calibration method. Peptides were dissolved in $\mathrm{H}_{2} \mathrm{O}$, and samples contained $10 \% \mathrm{D}_{2} \mathrm{O}$. Chemical shifts were referenced to 2,2 dimethyl-2-silapentane-5-sulfonate (DSS) as internal standard. Two dimensional ${ }^{1} \mathrm{H}-{ }^{1} \mathrm{H}$ correlation spectra: TOCSY, NOESY, and ROESY were measured by using standard Bruker pulse programs. Spectra were analyzed by the Sparky software.

Computational Details. Reference conformers (RCs) were collected via high energy molecular dynamics simulations in vacuum. Gromos $43 \mathrm{~b} 1$ force field was used with the simulation temperature set to $600 \mathrm{~K}$, Berendsen type temperature coupling ${ }^{52}$ with $\tau_{\mathrm{t}}=0.1$ and 1 fs time step. All bond lengths were constrained. ${ }^{53}$ The default values were used for other MD parameters as implemented in Gromacs 3.3.1..$^{54-56}$ Table 3 shows the simulation time required by the conformational search $\left(t_{\mathrm{vq}}\right)$, and the number of the obtained low energy reference conformers $\left(N_{\mathrm{RC}}\right)$ for the peptides which were subjected to QSAR analysis.

RCs were surrounded by water molecules, in the framework of the SPC model, and $\mathrm{Na}^{+}$and $\mathrm{Cl}^{-}$counterions were added to the side chains of His and Arg, respectively, to neutralize their charge at $\mathrm{pH}=7$. The average number of water molecules $\left(N_{\text {wat }}\right)$ added to each peptide is shown in Table 3. To equilibrate the solvent molecules, the peptide and the ions were kept frozen ${ }^{57}$ in the subsequent MD simulations, launched for all RCs, with the temperature set to $300 \mathrm{~K}$, time step to $2 \mathrm{fs}$ and the van der Waals and Coulomb cut offs to $1 \mathrm{~nm}$ for a $10 \mathrm{ps}$ simulation. Then, the solute and the ions were released, and simulations were carried out for $2 \times 0.2 \mathrm{~ns}$ simulation time. The first $0.2 \mathrm{~ns}$ were used to equilibrate the peptide structure in the solvent environment and were excluded from further analysis. Data mining was performed on the second $0.2 \mathrm{~ns}$ long simulation period for every RCs. The total trajectory length subjected to data mining for each peptide is shown $\left(t_{\text {sol }}\right)$ in Table 3.

The BC search algorithm was written in pure java and the standard ChemAxon tools ${ }^{58}$ were used, the trajectories and the anchor conformations were stored in a MySQL database. The CORE space for these 14 peptides was defined a priori as the backbone $\varphi$ and $\Psi$ dihedrals of the amino acid sequence FRHDSGY. The rmsd of the dihedral vectors was used as a diversity measure.

It has to be noted that the BC search using rmsd of the superimposed atomic coordinates of the CORE was beyond our 
computational capacity. From the same reason simple density cut off was utilized during the calculations, and no Gaussian weighting was applied.

After scanning ${ }^{24}$ the parameter space of the algorithm the following input values were utilized: the number of cycles per run $(N \rho)$ was set to 5 and in each cycle the best $20 \%$ of the ACs was accepted. The $\rho$ values were scaled down by 0.9 in each cycle. The initial $\rho$ value, the $\rho_{1}$, was set equal to $\delta$. The $\delta$ was set to $45^{\circ}$ dihedral angle rmsd. The number of runs launched from randomized sequence of conformations the $N_{\text {rand }}$ value was set to 20 . The ACs which had higher $q^{2}$ value than 0.6 were clustered.

Acknowledgment. This work has been partially supported by grants from the Deutsche Forschungsgemeinschaft and the EU network "Ligand Binders to the Human Proteome". The expert assistance by Dmitry Galetskiy and Reinhold Weber with FTICR mass spectrometery is gratefully acknowledged. The QSAR development was funded by the Agency for Research Fund Management and Research Exploitation: GVOP-AKF2004-3.1.1-0351. We acknowledge the support of the InfoPark Foundation, ChemAxon Ltd., Richter Ltd., and Gaussian, Inc. This work was also supported by GVOP-3.2.1.-2004-04-0005/ 3.0 and by the Hungarian National Science Fund (OTKA T 03456, D 48459).

Supporting Information Available: HPLC chromatograms and mass spectra of the compounds and temperature dependence of the ${ }^{1} \mathrm{H}$ chemical shift for three selected residues. This material is available free of charge via the Internet at http://pubs.acs.org.

\section{References}

(1) Weiner, H. L.; Lemere, C. A.; Maron, R.; Spooner, E. T.; Grenfell, T. J.; Mori, C.; Issazdeh, S.; Hancock, W. W.; Selkoe, D. J. Nasal administration of amyloid-beta peptide decreases cerebral amyloid burden in a mouse model of Alzheimer's disease. Ann. Neurol. 2000, $48,567-579$.

(2) Schenk, D.; Barbour, R.; Dunn, W.; Gordon, G.; Grajeda, H.; Guido, T.; Hu, K.; Huang, J. P.; Johnson-Wood, K.; Khan, K.; Kholodenko, D.; Lee, M.; Liao, Z. M.; Lieberburg, I.; Motter, R.; Mutter, L.; Soriano, F.; Shopp, G.; Vasquez, N.; Vandevert, C.; Walker, S.; Wogulis, M.; Yednock, T.; Games, D.; Seubert, P. Immunization with amyloid-beta attenuates Alzheimer disease-like pathology in the PDAPP mouse. Nature 1999, 400, 173-177.

(3) Janus, C.; Pearson, J.; McLaurin, J.; Mathews, P. M.; Jiang, Y.; Schmidt, S. D.; Chishti, M. A.; Horne, P.; Heslin, D.; French, J.; Mount, H. T. J.; Nixon, R. A.; Mercken, M.; Bergeron, C.; Fraser, P. E.; St. George-Hyslop, P.; Westaway, D. A beta peptide immunization reduces behavioural impairment and plaques in a model of Alzheimer's disease. Nature 2000, 408, 979-982.

(4) Bard, F.; Cannon, C.; Barbour, R.; Burke, R. L.; Games, D.; Grajeda, H.; Guido, T.; Hu, K.; Huang, J. P.; Johnson-Wood, K.; Khan, K.; Kholodenko, D.; Lee, M.; Lieberburg, I.; Motter, R.; Nguyen, M.; Soriano, F.; Vasquez, N.; Weiss, K.; Welch, B.; Seubert, P.; Schenk, D.; Yednock, T. Peripherally administered antibodies against amyloid beta-peptide enter the central nervous system and reduce pathology in a mouse model of Alzheimer disease. Nature Med. 2000, 6, 916919.

(5) DeMattos, R. B.; Bales, K. R.; Cummins, D. J.; Dodart, J. C.; Paul, S. M.; Holtzman, D. M. Peripheral anti-A beta antibody alters CNS and plasma A beta clearance and decreases brain A beta burden in a mouse model of Alzheimer's disease. Proc. Natl. Acad. Sci. U.S.A. 2001, 98, 8850-8855.

(6) Morgan, D.; Diamond, D. M.; Gottschall, P. E.; Ugen, K. E.; Dickey, C.; Hardy, J.; Duff, K.; Jantzen, P.; DiCarlo, G.; Wilcock, D.; Connor, K.; Hatcher, J.; Hope, C.; Gordon, M.; Arendash, G. W. A beta peptide vaccination prevents memory loss in an animal model of Alzheimer's disease. Nature 2000, 408, 982-985.

(7) McLaurin, J.; Cecal, R.; Kierstead, M. E.; Tian, X.; Phinney, A. L.; Manea, M.; French, J. E.; Lambermon, M. H. L.; Darabie, A. A.; Brown, M. E.; Janus, C.; Chishti, M. A.; Horne, P.; Westaway, D.; Fraser, P. E.; Mount, H. T. J.; Przybylski, M.; St George-Hyslop, P. Therapeutically effective antibodies against amyloid-beta peptide target amyloid-beta residues 4-10 and inhibit cytotoxicity and fibrillogenesis. Nature Med. 2002, 8, 1263-1269.
(8) Drakopoulou, E.; Uray, K.; Mezö, G.; Price, M. R.; Vita, C.; Hudecz, F. Synthesis and antibody recognition of mucin 1 (MUC1)-alphaconotoxin chimera. J. Peptide Sci. 2000, 6, 175-185.

(9) Hudecz, F. Manipulation of epitope function by modification of peptide structure: A minireview. Biologicals 2001, 29, 197-207.

(10) Mezö, G.; Drakopoulou, E.; Paál, V.; Rajnavölgyi, E.; Vita, C.; Hudecz, F. Synthesis and immunological studies of alpha-conotoxin chimera containing an immunodominant epitope from the 268-284 region of HSV gD protein. J. Peptide Res. 2000, 55, 7-17.

(11) Tugyi, R.; Mezö, G.; Fellinger, E.; Andreu, D.; Hudecz, F. The effect of cyclization on the enzymatic degradation of herpes simplex virus glycoprotein D derived epitope peptide. J. Peptide Sci. 2005, 11, 642649.

(12) Tugyi, R.; Uray, K.; Iván, D.; Fellinger, E.; Perkins, A.; Hudecz, F. Partial D-amino acid substitution: Improved enzymatic stability and preserved Ab recognition of a MUC2 epitope peptide. Proc. Natl. Acad. Sci. U.S.A. 2005, 102, 413-418.

(13) Wilkinson, K. A.; Vordermeier, M. H.; Kajtár, J.; Jurcevic, S.; Wilkinson, R.; Ivanyi, J.; Hudecz, F. Modulation of peptide specific $\mathrm{T}$ cell responses by non-native flanking regions. Mol. Immunol. 1997, 34, 1237-1246.

(14) Mezö, G.; de Oliveira, E.; Krikorian, D.; Feijlbrief, M.; Jakab, A.; Tsikaris, V.; Sakarellos, C.; Welling-Wester, S.; Andreu, D.; Hudecz, F. Synthesis and comparison of antibody recognition of conjugates containing herpes simplex virus type 1 glycoprotein D epitope VII. Bioconjugate Chem. 2003, 14, 1260-1269.

(15) Manea, M.; Mezö, G.; Hudecz, F.; Przybylski, M. Polypeptide conjugates comprising a beta-amyloid plaque-specific epitope as new vaccine structures against Alzheimer's disease. Biopolymers 2004, 76, 503-511.

(16) Manea, M.; Hudecz, F.; Przybylski, M.; Mezö, G. Synthesis, solution conformation, and antibody recognition of oligotuftsin-based conjugates containing a beta-amyloid(4-10) plaque-specific epitope. Bioconjugate Chem. 2005, 16, 921-928.

(17) Hopfinger, A. J.; Wang, S.; Tokarski, J. S.; Jin, B. Q.; Albuquerque, M.; Madhav, P. J.; Duraiswami, C. Construction of 3D-QSAR models using the 4D-QSAR analysis formalism. J. Am. Chem. Soc. 1997, 119, 10509-10524.

(18) Vedani, A.; Briem, K.; Dobler, M.; Dollinger, H.; McMasters, D. R. Multiple-conformation and protonation-state representation in 4DQSAR: The neurokinin-1 receptor system. J. Med. Chem. 2000, 43, 4416-4427.

(19) Martinek, T. A.; Ötvös, F.; Dervarics, M.; Tóth, G.; Fülöp, F. Ligandbased prediction of active conformation by 3D-QSAR flexibility descriptors and their application in $3+3 \mathrm{D}-\mathrm{QSAR}$ models. J. Med. Chem. 2005, 48, 3239-3250.

(20) Bhonsle, J. B.; Wang, Z. X.; Tamamura, H.; Fujii, N.; Peiper, S. C.; Trent, J. O. A simple, automated quasi-4D-QSAR, quasi-multi way PLS approach to develop highly predictive QSAR models for highly flexible CXCR4 inhibitor cyclic pentapeptide ligands using scripted common molecular modeling tools. QSAR Comb. Sci. 2005, 24, 620630.

(21) Bhonsle, J. B.; Bhattacharjee, A. K.; Gupta, R. K. Novel semiautomated methodology for developing highly predictive QSAR models: application for development of QSAR models for insect repellent amides. J. Mol. Model. 2007, 13, 179-208.

(22) Dervarics, M.; Otvos, F.; Martinek, T. A. Development of a chiralitysensitive flexibility descriptor for $3+3$ D-QSAR. J. Chem. Inf. Mod. 2006, 46, 1431-1438.

(23) Kalászi, A.; Farkas, Ö. Lead conformer prediction based on a library of flexible molecules. THEOCHEM 2003, 666, 645-649.

(24) Kalászi, A.; Imre, G.; Jákli, I.; Farkas, Ö. Identification of the bioactive conformation for mucin epitope peptides. THEOCHEM 2007, 823, $16-27$.

(25) Janssen, L. H. M. Conformational flexibility and receptor interaction. Bioorg. Med. Chem. 1998, 6, 785-788.

(26) Yung-Chi, Cheng.; Prusoff, W. H. Relationship between the inhibition constant $(\mathrm{Ki})$ and the concentration of inhibitor which causes $50 \%$ inhibition (I50) of an enzymatic reaction. Biochem. Pharmacol. 1973, 22, 3099-3108.

(27) Nicklaus, M. C.; Wang, S. M.; Driscoll, J. S.; Milne, G. W. A. Conformational-changes of small molecules binding to proteins. Bioorg. Med. Chem. 1995, 3, 411-428.

(28) Perola, E.; Charifson, P. S. Conformational analysis of drug-like molecules bound to proteins: An extensive study of ligand reorganization upon binding. J. Med. Chem. 2004, 47, 2499-2510.

(29) Stockwell, G. R.; Thornton, J. M. Conformational diversity of ligands bound to proteins. J. Mol. Biol. 2006, 356, 928-944.

(30) Steer, D.; Lew, R.; Perlmutter, P.; Smith, A. I.; Aguilar, M. I. Inhibitors of metalloendopeptidase EC 3.4.24.15 and EC 3.4.24.16 stabilized against proteolysis by the incorporation of beta-amino acids. Biochemistry 2002, 41, 10819-10826. 
(31) Briand, J. P.; Benkirane, N.; Guichard, G.; Newman, J. F. E.; vanRegenmortel, M. H. V.; Brown, F.; Muller, S. A retro-inverso peptide corresponding to the GH loop of foot-and-mouth disease virus elicits high levels of long-lasting protective neutralizing antibodies. Proc. Natl. Acad. Sci. U.S.A. 1997, 94, 12545-12550.

(32) Hamamoto, K.; Kida, Y.; Zhang, Y.; Shimizu, T.; Kuwano, K Antimicrobial activity and stability to proteolysis of small linear cationic peptides with D-amino acid substitutions. Microbiol. Immunol. 2002, 46, 741-749.

(33) Conley, A. J.; Conard, P.; Bondy, S.; Dolan, C. A.; Hannah, J.; Leanza, W. J.; Marburg, S.; Rivetna, M.; Rusiecki, V. K.; Sugg, E. E.; Vanmiddlesworth, F.; Warne, S. A.; Ulrich, J. T.; Rudbach, J. A.; Tolman, R. L.; Emini, E. A. Immunogenicity of Synthetic Hiv-1 Gp120 V3-Loop Peptide-Conjugate Immunogens. Vaccine 1994, 12, 445451.

(34) Muller, S.; Plaue, S.; Samama, J. P.; Valette, M.; Briand, J. P.; van Regenmortel, M. H. V. Antigenic properties and protective capacity of a cyclic peptide corresponding to site-A of Influenza-virus hemagglutinin. Vaccine 1990, 8, 308-314.

(35) Schulzegahmen, U.; Klenk, H. D.; Beyreuther, K. Immunogenicity of loop-structured short synthetic peptides mimicking the antigenic site A of Influenza-virus hemagglutinin. Eur. J. Biochem. 1986, 159, 283-289.

(36) Williams, W. V.; Kieberemmons, T.; Vonfeldt, J.; Greene, M. I.; Weiner, D. B. Design of bioactive peptides based on antibody hypervariable region structures - development of conformationally constrained and dimeric peptides with enhanced affinity. J. Biol. Chem. 1991, 266, 5182-5190.

(37) Schlosser, G.; Mezö, G.; Kiss, R.; Vass, E.; Majer, Z.; Feijlbrief, M.; Perczel, A.; Bösze, S.; Welling-Wester, S.; Hudecz, F. Synthesis, solution structure analysis and antibody binding of cyclic epitope peptides from glycoprotein D of Herpes simplex virus type I. Biophys. Chem. 2003, 106, 155-171.

(38) Valero, M. L.; Camarero, J. A.; Haack, T.; Mateu, M. G.; Domingo, E.; Giralt, E.; Andreu, D. Native-like cyclic peptide models of a viral antigenic site: finding a balance between rigidity and flexibility. $J$. Mol. Recognit. 2000, 13, 5-13.

(39) van Regelmortel M. H. V.; Briand, J. P.; Muller, S.; Plaue, S. In Laboratory techniques in biochemistry and molecular biology; Burdon, R. H., Knippenberg, P. H., Eds.; Elsevier: Amsterdam, The Netherlands: 1988; pp 145-158.

(40) Buck, M. Trifluoroethanol and colleagues: cosolvents come of age. Recent studies with peptides and proteins. Q. Rev. Biophys. 1998, 31, 297-355.

(41) Goodman, M.; Listowsky, I. Conformational aspects of synthetic polypeptides VI. Hypochromic spectral studies of oligo- $\gamma$-methyl-Lglutamate peptides. J. Am. Chem. Soc. 1962, 84, 3770-3771.
(42) Nelson, J. W.; Kallenbach, N. R. Stabilization of the ribonuclease S-peptide $\alpha$ helix by trifluoroethanol. Proteins 1986, 1, 211-217.

(43) Woody, R. W. In Circular dichroism - Principles and applications; Woody, R. W., Nakanishi, K., Berova, N., Eds.; VCH Publishers, Inc.: New York, 1996; pp 473-496.

(44) Vass, E.; Hollósi, M.; Besson, F.; Buchet, R. Vibrational spectroscopic detection of beta- and gamma-turns in synthetic and natural peptides and proteins. Chem. Rev. 2003, 103, 1917-1954.

(45) Woody, R. W. In The peptides-Analysis, Synthesis, Biology; Udenfriend, S. Meienhofer, J., Eds.; Academic Press, Inc.: New York, 1985; pp 15-114.

(46) Uray, K.; Kajtár, J.; Vass, E.; Price, M. R.; Hollósi, M.; Hudecz, F. Effect of D-amino acid substitution in a mucin 2 epitope on mucinspecific monoclonal antibody recognition. Arch. Biochem. Biophys. 2000, 378, 25-32.

(47) Cheng, R. P.; Gellman, S. H.; DeGrado, W. F. beta-peptides: From structure to function. Chem. Rev. 2001, 101, 3219-3232.

(48) Iverson, H. A.; Fox, D., III; Nadler, L. S.; Klevit, R. E.; Nathanson, N. M. Identification and structural determination of the M3 muscarinic acetylcholine receptor baselatoral sorting signal. J. Biol. Chem. 2005, $280,24568-24575$

(49) Heisterberg, D. J. Quaternion fit source code. http://www.ccl.net/ cca/software/SOURCES/C/quaternion-mol-fit/quatfit. 1990.

(50) Barnard, J. M.; Downs, G. M. Chemical fragment generation and clustering software. J. Chem. Inf. Comput. Sci. 1997, 37, 141-142.

(51) Brown, R. D.; Martin, Y. C. Use of structure Activity data to compare structure-based clustering methods and descriptors for use in compound selection. J. Chem. Inf. Comput. Sci. 1996, 36, 572-584.

(52) Berendsen, H. J. C.; Postma, J. P. M.; Vangunsteren, W. F.; Dinola, A.; Haak, J. R. Molecular-dynamics with coupling to an external bath. J. Chem. Phys. 1984, 81, 3684-3690.

(53) Hess, B.; Bekker, H.; Berendsen, H. J. C.; Fraaije, J. G. E. M. LINCS: A linear constraint solver for molecular simulations. J. Comput. Chem. 1997, 18, 1463-1472.

(54) Berendsen, H. J. C.; Vanderspoel, D.; Vandrunen, R. Gromacs - A message-passing parallel molecular-dynamics implementation. Comput. Phys. Commun. 1995, 91, 43-56.

(55) Lindahl, E.; Hess, B.; van der Spoel, D. GROMACS 3.0: a package for molecular simulation and trajectory analysis. J. Mol. Modeling 2001, 7, 306-317.

(56) van der Spoel, D.; Lindahl, E.; Hess, B.; Groenhof, G.; Mark, A. E.; Berendsen, H. J. C. GROMACS: Fast, flexible, and free. J. Comput. Chem. 2005, 26, 1701-1718.

(57) Miyamoto, S.; Kollman, P. A. Settle - an analytical version of the shake and rattle algorithm for rigid water models. J. Comput. Chem. 1992, 13, 952-962

(58) ChemAxon MarvinBeans 4.1.0. http://www.chemaxon.com, 2007. 